\title{
Las noticias impresas sobre Polonia en la España de la Edad Moderna*
}

\section{Printed News about Poland in the Spain of the Golden Age}

\section{Nieves Pena Sueiro}

https://orcid.org/0000-0003-2028-2765

Universidade da Coruña

ESPAÑA

nieves.pena.sueiro@udc.es

\section{Mónica Martín Molares}

https://orcid.org/0000-0002-1696-9452

Universidade da Coruña

ESPAÑA

monica.martin.molares@udc.es

\section{Javier Ruiz Astiz}

https://orcid.org/0000-0002-3703-7398

Universidade da Coruña

ESPAÑA

j.ruiz.astiz@udc.es

[Hipogrifo, (issn: 2328-1308), 9.1, 2021, pp. 329-372]

Recibido: 04-03-2021 / Aceptado: 19-04-2021

DOl: http://dx.doi.org/10.13035/H.2021.09.01.21

Resumen. Las bibliotecas históricas y archivos conservan un buen número de noticias impresas en los territorios de la antigua Monarquía Hispánica sobre sucesos ocurridos en el reino de Polonia, lo que, sin duda, evidencia el interés que

* Este trabajo se ha realizado en el marco del proyecto de investigación Biblioteca Digital Siglo de Oro 6 (BIDISO 6), PID2019-105673GB-I00 (01/06/2020 a 31/05/2023), financiado por el Ministerio de Ciencia e Innovación del Gobierno de España. El proyecto BIDISO se enmarca en la investigación llevada a cabo en el seno del grupo HISPANIA (G000208) de la Universidade da Coruña, que ha conseguido una ayuda de consolidación de la Xunta de Galicia para el período 2019-2021 (ref. ED431B 2019/28). Una primera versión de la investigación sobre este tema se presentó en el Congreso Internacional España y Europa del Este: miradas recíprocas, celebrado en la Universidad de Varsovia entre los días 18 y 20 de octubre de 2018. 
suscitaban. El objetivo de este trabajo es profundizar en las características de esa literatura informativa a partir del análisis de los datos almacenados en el Catálogo y Biblioteca Digital de Relaciones de Sucesos (CBDRS), que hasta el momento ofrece un corpus de ciento diecinueve impresos noticieros. De la lectura de los textos y su estudio se desprende qué temas interesaban, quiénes intervenían en el proceso de creación y publicación de la información (autores, traductores, impresores, editores) y los lugares y fechas de edición. Se constata que hubo un circuito informativo entre Polonia y España que proveía de noticias a toda la Península a través del correo y del buen hacer de diplomáticos y religiosos, los cuales cumplían con la obligación de dar cuenta a sus superiores. Dichas noticias circularon por la geografía hispana impresas en talleres radicados en distintas ciudades peninsulares, lo que evidencia el interés que despertó lo acaecido en Polonia al tratarse de un aliado natural de la Monarquía Hispánica frente al enemigo otomano.

Palabras clave. Impresos noticieros; CBDRS; Polonia; España; Siglos de Oro.

Abstract. Historical libraries and archives keep a good number of news printed in the territories of the former Hispanic Monarchy on events that occurred in the kingdom of Poland, which undoubtedly shows the interest they aroused. The objective of this work is to delve into the characteristics of this informative literature based on the analysis of the data stored in the Catalog and Digital Library of News Pamphlets (CBDRS), which offers a corpus of ninety-four newsletters. From the reading of the texts and their study it is clear which topics were of interest, who were involved in the process of creating and publishing the information (authors, translators, printers, publishers) and the places and dates of publication. It is found that there was an informative circuit between Poland and Spain that provided news to the entire Peninsula through the mail and the good work of diplomats and religious, who fulfilled the obligation to report to their superiors. Said news circulated throughout the Hispanic geography printed in workshops located in different peninsular cities, which shows the interest that what happened in Poland aroused as it was a natural ally of the Hispanic Monarchy against the Ottoman enemy.

Keywords. News pamphlets; CBDRS; Poland; Spain; Golden Age.

\section{POLONIA EN ESPAÑA: UNA ALIANZA TEJIDA A TRAVÉS DE IMPRESOS EN EL CBDRS}

Las relaciones entre la Monarquía Hispánica y Polonia durante la Edad Moderna no han sido estudiadas en toda su riqueza y complejidad', si bien debe apuntarse que en los últimos treinta años han experimentado un notable desarrollo que perdura hasta la actualidad ${ }^{2}$. No hay duda de que la emergencia del nuevo espacio

1. Véase Eminowick, 2004.

2. Resultan de notable interés los trabajos de Beata Baczyńska (2005), Ryszard Skowron (2008 y 2017), Marta Piłat Zuzankiewicz (2015), Matylda Urjasz-Raczko (2014), Cezary Taracha (2001), Grzegorz Bąk (2001) o Miguel Conde Pazos (2014), entre otros, cuyas referencias completas pueden encontrarse en la bibliografía final. De manera particular, para el estudio de la literatura noticie- 
transdisciplinar de las Humanidades Digitales, que utiliza los últimos avances tecnológicos para responder a cuestiones y ofrecer soluciones a los retos y desafíos de las Ciencias Humanas, supone una gran ayuda, no solo porque facilita el acceso y consulta de fuentes primarias, sino que también permite la construcción y consulta de bases de datos, bancos de imágenes para almacenar esa información y contribuye a la preservación del patrimonio bibliográfico y documental.

Desde mediados de la década de los noventa del siglo xx en España comenzaron su andadura proyectos de investigación con equipos interdisciplinares que propiciaron la creación de bases de datos, bibliotecas y archivos digitales especializados, diseñados con el doble objetivo de construir herramientas específicas para la investigación y de conformar instrumentos generadores de nuevo conocimiento. Sin embargo, no fue hasta 2011, aproximadamente, cuando se comenzaron a desarrollar las Humanidades Digitales en España ${ }^{3}$.

A partir de entonces se han multiplicado los proyectos de investigación, estudios y publicaciones derivadas de ellos, lo que ha dado lugar a un gran avance en el conocimiento en diversas disciplinas como Literatura Española, Historia de la Comunicación, Lingüística, Lexicografía, Geografía, etc. En este contexto, se han puesto en marcha un número importante de recursos y herramientas para el estudio humanístico, desarrollando aplicaciones, bibliotecas digitales, bases de datos y agregadores de sitios de interés, bien temáticos, bien por países.

Precisamente uno de esos proyectos de investigación, el Catálogo y Biblioteca Digital de Relaciones de Sucesos -en adelante, CBDRS - ofrece datos muy interesantes para el progreso en la investigación sobre Historia de la Comunicación en general, y particularmente para el estudio de las relaciones entre España y Polonia en la Edad Moderna. El CBDRS es una base de datos y biblioteca digital que reúne información bibliográfica sobre impresos noticieros publicados entre los siglos XV al XVIII y conservados en bibliotecas de todo el mundo. Ofrece, de manera gratuita a través de Internet, la descripción bibliográfica de las obras, la identificación de ediciones, la localización de ejemplares, y, cuando es posible, la reproducción digital facsimilar y/o el texto transcrito de algunos ${ }^{4}$.

ra polaca es fundamental la consulta de la Biblioteca digital de impresiones efímeras polacas de los siglos XVI, XVII Y XVIII que contiene todas las ediciones que se conservan descritas en publicaciones científicas. La lista se compiló sobre la base del trabajo de Konrad Zawadzki, Gazety ulotne polskie i Polski dotyczące od XVI-XVIII wieku, el cual comprende alrededor de 2.500 entradas bibliográficas. La base de datos permite realizar búsquedas según múltiples criterios, incluidos los que se utilizan normalmente en las descripciones bibliográficas (en su mayoría tomadas de K. Zawadzki), así como otras menos habituales (temáticas, relacionadas con el género y otras). El repositorio se encuentra en el servidor del Instituto de Periodismo de la Universidad de Varsovia.

3. López Poza, 2015.

4. En varios trabajos anteriores (Pena Sueiro y Álvarez García, 2014; Pena Sueiro, 2017 y Pena Sueiro y Saavedra Places, 2019) puede consultarse la historia y configuración de este catálogo y biblioteca digital, las utilidades de su uso, así como los resultados de analizar gran cantidad de datos sobre el objeto de estudio que, cruzados adecuadamente, nos permiten obtener resultados y conclusiones impensables hasta hace pocos años. El CBDRS es fruto del trabajo continuado, desde hace más de 24 años, de un equipo interdisciplinar de la Universidade da Coruña, que creó Sagrario López Poza en 1994. El 


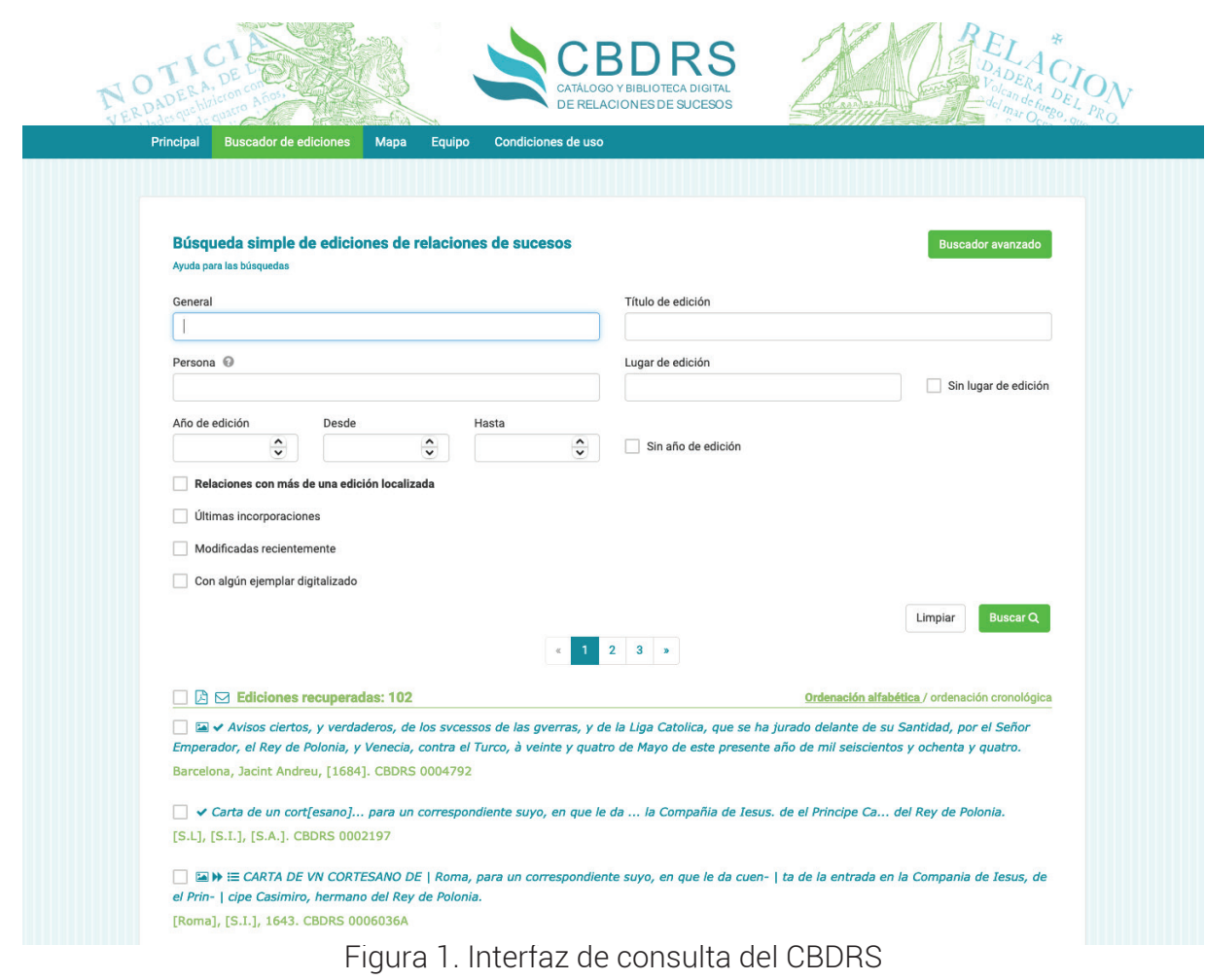

En el año 2017 el CBDRS se dotó de un sistema de geolocalización que permite realizar consultas de manera directa sobre un mapa, bien por lugar de impresión o por lugar de acontecimiento de la noticia ${ }^{5}$; además, puede hacerse también una

equipo fue pionero en la aplicación de las Humanidades Digitales en España. En la actualidad lo forman investigadores de catorce instituciones y, además, cuenta con la colaboración de instituciones públicas como Catálogo Colectivo del Patrimonio Bibliográfico Español, Biblioteca Nacional de España, Biblioteca de la Real Academia Española, Biblioteca de la Universidad de Barcelona, Biblioteca Universitaria de Sevilla, etc., las cuales muy generosamente aportan datos y contribuyen a ampliar y mejora el catálogo. 5. Debe advertirse que los trabajos de geolocalización de los lugares de acontecimientos históricos plantean algunas dificultades no siempre fáciles de resolver, y que pasan necesariamente por la inversión de un tiempo de investigación geográfica e histórica y el desarrollo de ontologías. Es esa la razón de que las búsquedas no siempre ofrezcan resultados exactos. Piénsese, por ejemplo, que cuando tratamos con toponimia histórica podemos encontrarnos con lugares que ya no existen, o que forman parte de un territorio con una configuración distinta a la actual; podría ser, también, que el nombre de un topónimo haya variado o que haya evolucionado de manera anormal; otra fuente de problemas son las malas traducciones, etc. En el caso que nos ocupa, la literatura informativa sobre Polonia, resulta especialmente difícil averiguar el nombre o el lugar exacto de los sucesos en las guerras contra los turcos, entre otras cosas, porque no existía todavía fijación gráfica o quien tradujo el topónimo, lo españolizó, a veces a partir de una traducción italiana ya viciada. Para este tipo de proyectos es más necesaria que nunca la colaboración internacional e interdisciplinar. Y por eso debemos agradecer la ayuda que, en ese sentido, ha prestado al CBDRS la doctora Marta Piłat Zuzanckiewick (Universidad de Varsovia) para geolocalizar algunos lugares de Europa del Este. 
búsqueda temporal por fechas de edición o acontecimiento, e incluso una búsqueda combinada (búsqueda geográfica y búsqueda por fecha del acontecimiento o de la edición, según se prefiera). Para su manejabilidad la cartografía de base es de Open Street Map ${ }^{6}$, ya que posee una licencia de uso libre.

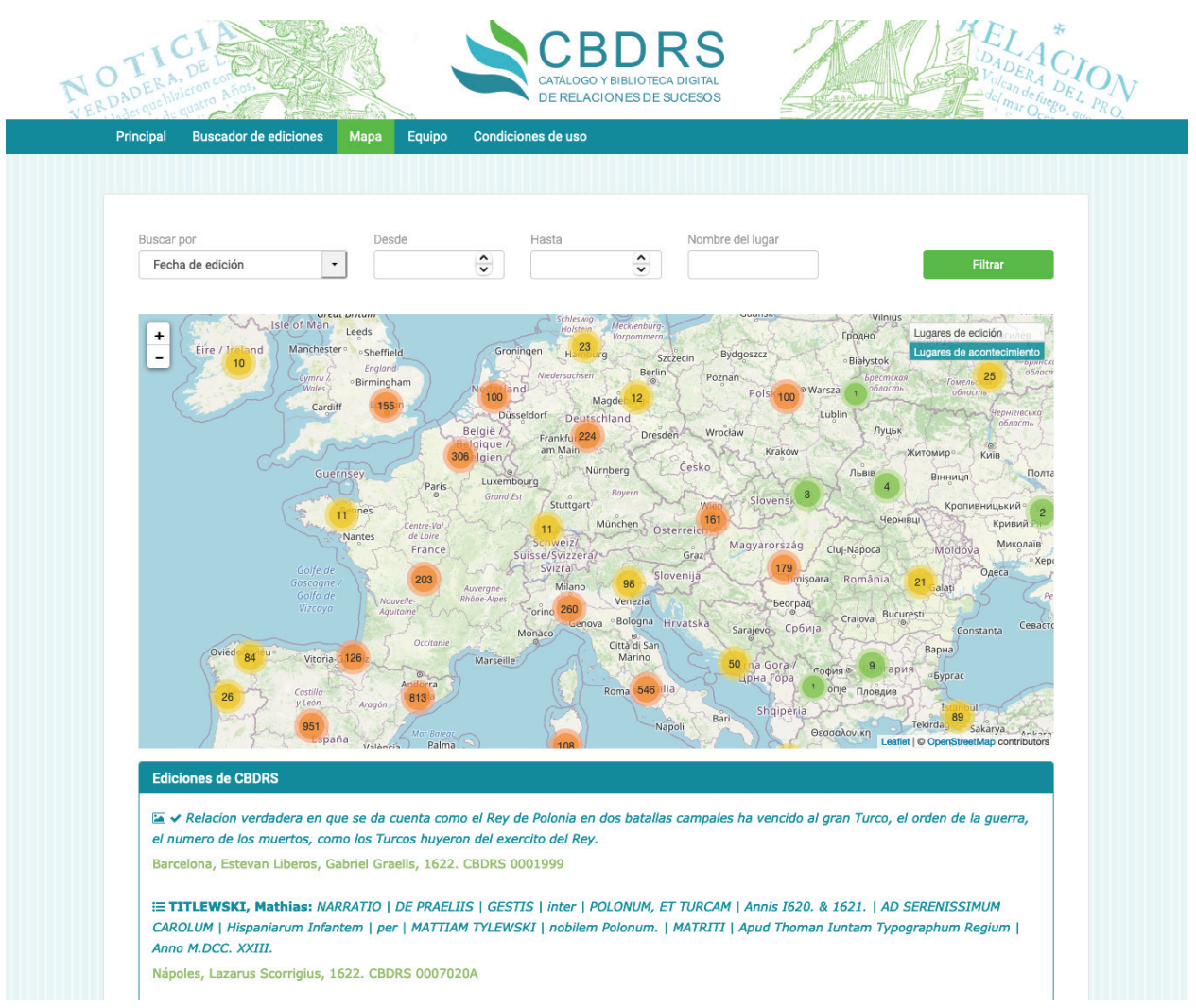

Figura 2. Geolocalización de Relaciones de sucesos (CBDRS)

En el mes de diciembre de 2020, el CBDRS almacenaba información de ciento diecinueve impresos con noticias sobre Polonia impresas en territorio hispano?. Consideramos que con este número de ediciones podríamos obtener datos indicativos, resultado de la lectura y análisis de los textos, para el estudio de las relaciones políticas, históricas, literarias o comunicativas entre ambos países.

6. Open Street Map, https://www.openstreetmap.org [fecha de consulta: 14/10/2017].

7. Los datos pueden consultarse en el apéndice final de este trabajo, además de en Internet (haciendo una consulta en la base de datos o en el mapa que geolocaliza las noticias). 


\section{LAS NOTICIAS SOBRE POLONIA: CARACTERÍSTICAS EDITORIALES}

En una primera aproximación, al realizar una consulta por lugar de acontecimiento de los sucesos, los resultados que obtenemos son los siguientes: de los más de cien impresos noticieros, la mayor parte ofrecen información relacionada con el territorio polaco en general ( $y$ una vez que analicemos los temas predominantes en estos textos, entenderemos la razón); solo quince relatan sucesos que tienen lugar en Varsovia ${ }^{8}$ o cuya información procede de allí, y dos en Cracovia9

Una lectura de los textos y el análisis temático nos permiten la clasificación tipológica de las noticias atendiendo al tema que tratan. Y así nos encontramos con la siguiente distribución temática: 108 impresos de naturaleza político-militar, 6 con información sobre sucesos extraordinarios (nacimientos de monstruos, desgracias personales, etc.) y 5 sobre ceremonias y festejos. El siguiente gráfico permite visualizar bien el claro predominio (un $91 \%$ del total) de los temas político-militares ${ }^{10}$.

Gráfico 1. Tipología de las noticias sobre Polonia en España

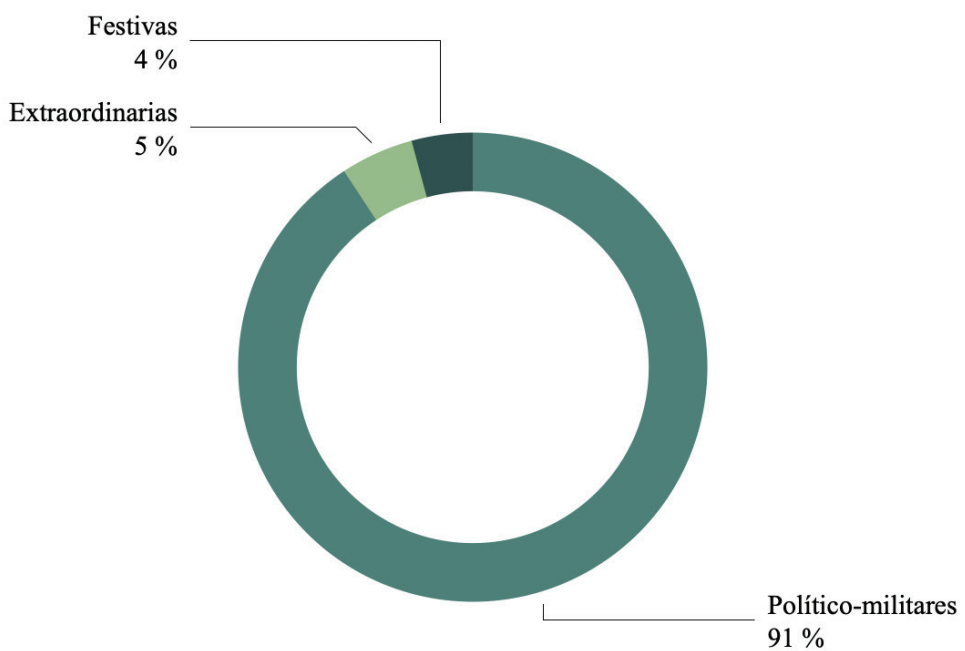

Es evidente que las guerras de religión contra protestantes, cismáticos, y, sobre todo, contra el enemigo turco, convirtieron a Polonia en bastión de la lucha religiosa y, al mismo tiempo, en un aliado perfecto de la Monarquía Hispánica. Esto se trasluce, al menos, de la gran mayoría de los impresos rescatados del CBDRS. Sirvan como ejemplo las siguientes noticias, contenidas en las figuras 3 y 4 (entradas 39 y 57 , respectivamente).

8. Se remite a la numeración de las noticias en el apéndice: 1, 8, 10, 11, 12, 13, 20, 22, 23, 24, 26, 27, 79, 91 y 93.

9. Entradas 14 y 41 del apéndice.

10. Esta prevalencia de las noticias de cariz político-militar también se advierte para los impresos sobre los otomanos. Así, según Carabias Torres (2010, p. 12) entre 1470 y 1850 calcula que el $77 \%$ de los textos publicados en España relacionados con los turcos hablaban de batallas, paces, treguas, etc. 

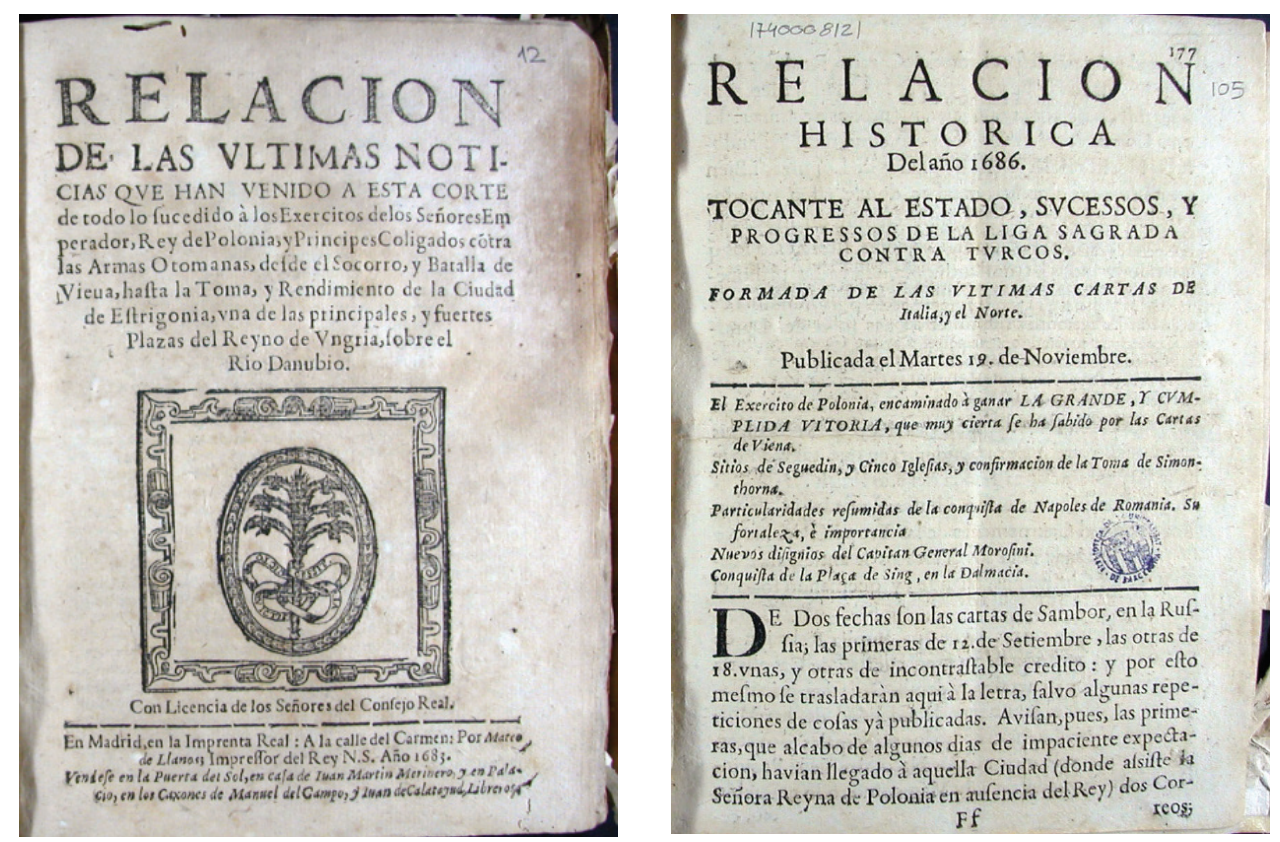

Figuras 3 y 4. Portadas de dos relaciones políticas (CBDRS0000874 y CBDRS0004959)

Lógicamente, el convulso siglo XVII por el elevado número de guerras, asedios, escaramuzas, así como acuerdos y tratados de paz, provoca que los relatos histórico-políticos sean los más abundantes. No debemos olvidar que Polonia era un actor protagonista en la frontera contra el turco, por lo que en la década de los ochenta de dicha centuria - como se verá- adquirió un papel fundamental, de ahí que lo acontecido en aquella zona de Europa interesase en España y se llevase a la imprenta. Quizás el ejemplo más paradigmático lo constituye un buen número de relaciones, de publicación seriada, que bajo el título de Relación histórica del año..., más la coletilla final de los progresos de la liga sagrada contra Turcos (Fig. 4), se editaron en Madrid entre 1683 y 1689 en la imprenta de Antonio Román por encargo del navarro Sebastián de Armendáriz, quien estaba afincado en la corte madrileña. Se nutrían, entre otras fuentes, de cartas: «las cartas de Polonia nos alegran con las noticias ciertas de la relevantísima ventaja que últimamente ganaron las armas de aquel gran rey, y poderosa república de los infieles, junto a Kameniez, y del movimiento y rotura de los persianos contra los mesmos otomanos» ${ }^{11}$.

11. Relaciones extraordinarias de la feliz, e importante vitoria. Consegida de las reales Armas de PoIonia contra vn Exercito de Turcos, encaminados al socorro de la Ciudad de Kameniez... (entrada 98, CBDRS0000933). 
No obstante, el responsable de esta publicación seriada, que ofrecía información de la guerra contra los turcos cada martes en Madrid, fue Francisco Fabro Bremundán, secretario de Juan de Austria (hermano bastardo del Felipe IV, rey de España) y verdadero artífice de su campaña propagandística, pues fue un personaje clave en el desarrollo de la información periódica en España ${ }^{12}$.

Al margen de esto, pueden documentarse en el CBDRS trece ediciones de relaciones de sucesos extraordinarios, que, curiosamente, narran extraños casos sucedidos en Polonia cuya interpretación es siempre político-religiosa. Así, el nacimiento de un monstruo pescado en un río del reino de Polonia fue un acontecimiento que despertó gran interés, como lo demuestra el impacto que tuvo la noticia en la época ${ }^{13}$. Conocemos, por lo menos, tres relaciones sobre el tema, cada una con varias ediciones en Sevilla, Granada, Barcelona o Lima.

Una de estas relaciones, que se publicó como anónima (con número de registro CBDRS0006544) ${ }^{14}$, relata el suceso y muestra, a través de un grabado, la representación del monstruo. De la misma se conservan dos ediciones de Sevilla y Granada publicadas en 1624. De otra de las relaciones (CBDRS0003473), cuyo autor es Juan Bautista de Morales, se conocen dos ediciones sevillanas en 1624 (Fig. 9, entrada 111) y una limeña en 1625. Todavía sobre el mismo suceso se imprimió en Barcelona en 1624 el Pronóstico y explicación de las siete letras que se hallaron en el montruo [sic] que apareció cerca de la ciudad de Varuasia en el Reyno de Polonia (Fig. 5, entrada 35), en el que ya se advierte:

Y este monstruo viene a confirmar lo referido y explicado acerca de dichas siete letras, por donde se ha de creer que la majestad divina, de cansado de aguardar tanta protervidad y desalumbramiento en la fe cristiana, enviara ha dicho y otros reinos el castigo merecido, aunque le cuesten tanto como nosotros, que le amamos y reconocemos por verdadero Señor. Si bien notando como conviniere, animando para la destrucción de tan bárbara gente a nuestro rey Felipe, para que con su santo celo y poder, los destruya, aumentando nuestra santa fe católica para siempre.

12. Fabro Bremundán, de origen borgoñón, y buen conocedor de lenguas (fue secretario mayor de lenguas) no solo estuvo vinculado a la creación de la Gaceta de Madrid, sino que, además, en 1677 obtuvo el privilegio exclusivo para su impresión. Asimismo, se ocupaba de publicar relaciones ocasionales, o incluso seriadas, sobre temas de interés, como los sucesos de Portugal o la llegada de Mariana de Neoburgo a España para casarse con Carlos II y su viaje desde el puerto de Ferrol hasta Madrid.

13. Y también en el siglo XX, pues varios estudiosos han tratado el tema del monstruo pescado de Polonia. Véanse Ettinghausen, 1995; Río Parra; 2003; Mancera Rueda y Galbarro García, 2015; Tropé, 2017. 14. Véanse en el apéndice las entradas 104 y 105. 

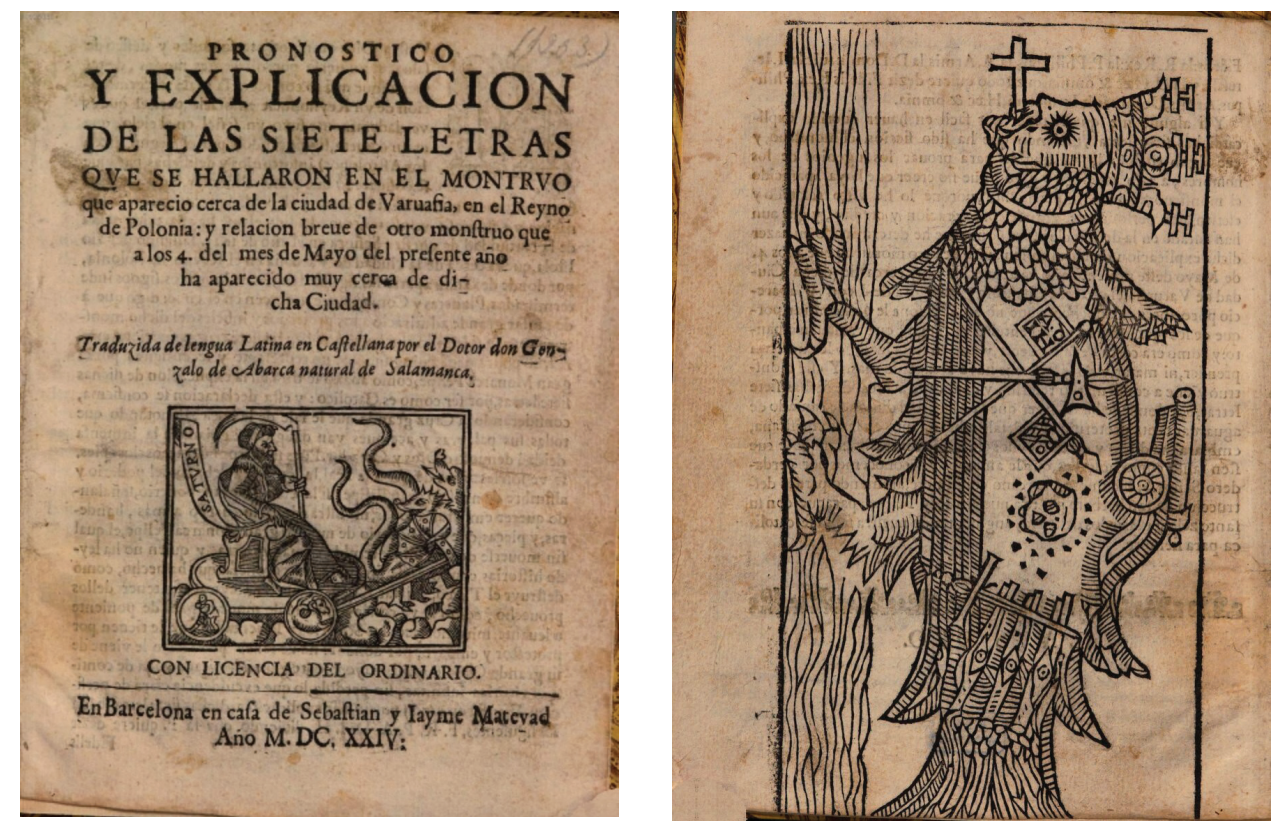

Figura 5. Portada del Pronóstico y explicación de las siete letras... y grabado del monstruo (CBDRS0006431)

Pero, no siendo bastante la inquietud generada por la presencia de monstruos en Polonia, si hacemos caso de lo que nos cuentan estos papeles noticieros, sucedieron todavía más fenómenos extraños. En 1627, una imagen de un Cristo, alcanzada por una bala de los herejes, manó sangre por espacio de siete días, según sabemos por la Relación verdadera de un caso raro y maravilloso sucedido en el Reyno de Polonia, para confirmación de nuestra santa Fe Catholica y confusión de los herejes que con tanta instancia han procurado y quieren contradecir a ella, donde trata como los herejes tiraron de balassos a un Santo Christo, el qual manó sangre por espacio de siete días del lado... publicada en Barcelona por Estevan Liberos y Gabriel Graells (entrada 96). Y años después, en 1674, se publicó otra relación que daba cuenta del nacimiento de un hombre monstruoso:

un Gigante tan alto que competía con los mas altos peñascos de la bóveda de la cueva, su altitud pasaba de veinte codos, de rostro feroz cabello crespo y corto, un solo ojo en medio de la frente, la barba negra y larga, cuyo pelo llevaba divido en dos greñas; e ropaje tan silvestre que era de mal compuestas pieles de diferentes fieras.

La Carta nveva del mas prodigioso svcesso que se ha visto, y monstruosidad de hombre que se ha hallado: Sucedido en el Reyno de Polonia, fue publicada en Barcelona por Josep Forcada (entrada 3). Pero en este caso, para tranquilidad de la cristiandad, era un monstruo amable, al que capturaron y enseñaron estilos de guerra para llevarle a pelear contra el turco, pues tenía mucha fuerza: 
Tiénesele un faraute para que le enseñe la lengua polaca, enséñanle también los estilos de guerra, a que lleva el gigante muy grande afición. Y es cierto que irá también a pelear contra el turco, porque es gigante de grande fuerza, el cual hasta ahora no se sabe de do ha salido, ni como ha venido a parar en aquel monte tan áspero. Dios quiera sea para la total ruina del turco; para que se aumenten las fuerzas en Polonia, continuando en sus victorias, por aumento de la santa fe, así sea. Amen.

Como puede comprobarse, la lectura atenta de estos textos nos deja ver que estas relaciones de sucesos extraordinarios contienen un discurso político implícito muy relacionado con las circunstancias de la Monarquía hispánica, y se utilizaron como un instrumento para el adoctrinamiento o creación de opinión pública ${ }^{15}$.

Por lo que se refiere a las relaciones de temática festiva sobre asuntos polacos, hasta el momento son solamente cinco las registradas. En ellas se da noticia de la coronación de Juan Casimiro, príncipe de Polonia (Fig. 6, entrada 106), el aparato con el que celebraron la Dieta en 1683 en la ciudad de Varsovia (entrada 73) o de las celebraciones por la victoria contra el Imperio Otomano por parte del rey de Polonia, que se editaron en Sevilla y Madrid (entradas 38, 99 y 109). Es curioso observar que en las relaciones sobre la victoria polaca, se combina la información con otra de asuntos festivos locales: entradas o salida a caballo en Madrid de Felipe IV y Carlos II, o, en la edición sevillana, la fiesta que la ilustrísima hermandad, que siempre fervorosa asiste al culto del Santísimo Sacramento en el templo del señor san Clemente, sagrario de la Santa Patriarcal y Metropolitana I glesia de Sevilla, hizo en acción de gracias de la célebre victoria, con que favoreció a Dios nuestro Señor las Armas del señor Emperador, gobernadas por el señor Rey de Polonia, y su Alteza el señor Duque de Lorena, contra el poder Otomano, teniendo sitiada la Plaza de Viena, este año de 1683 (entrada 109).

15. Como explica bien, para el caso de las relaciones de cometas, Usunáriz Garayoa, 2016, p. 51. 


\section{幽 \\ VER D A D E R A RELACION DE LA CORONACIONDELSERENISS" IV A N CASIMIRO, PRINCIPE DE POLONIA,POR MVERTE DEL PODEROSISSIMO REX VLADISLAO RVARTO.}

Sacada ficlmente de la carta que ha venido al Excelentif́simo leñot Émbaxador de aquel Re yno.Aqui fe declara las fi:ftas que fe hizieron,ceremonias con que le coronaron, Principes que le afsitieron, y Reynos que obedecen aquella facra Corona. Reducido a verfo por orden de fu Excelencia por Francif́co Alfantega y Cortes.

Con licencia en Madrid, por lulian de Partdes. Año de 1649.

T A celebre Polonia, à quiē aclama muerto Vladiflao IV. en quien infiero, L vico objeto la bolacil fama, ferIV. en nöbre,en hechos el piinero, preclara fiempec, de la Fédetiofa, lu perdida llorò t mas como via de la embidia terror, del Turco ofenfa, que en fu Principe Fenix renacia, coluna de la Iglefia Sacrofanta, de lospefames hizo parabienes, que hafta los mifmos ciclos la leuanta. Ilorò lus males, y eftimò fus bienes: Cuyes inuictos foberanos Reycs, Viendō̄ Vladinlao, Marte Chrintiano, dedican à la Ley de Dios fús leyes. folo à la muerte fe concede humano. Cujo titulo es fer poderofifsimus, En ci hetoico, pues, Ituan Cafimiro, y de tan gran veneracion dignilsimos, es cada intento cōtra el Turco vn tiro. que de fus hechos no alcāçò las fumas, A cuyo digno aplaufo combocados, la embıdia en légu as, ni la faına en plu. Electores, con Principes, y ERajus, J'olonia en fin,aquella (mas. de fu coronacion tratsn el modo, que Oromanos defignios atropella, y lucediò con tanta dicha todo, cuy os hijos valientes, y alentados, que en las partes del Principe le via fi enfeñan en la cuna a fer foldados. quan de jufticia la eleccion fi hazia. Mluertoliu gran Monarca, Congregòfe en fu Corte, qै es Varfauia, ąuc con fanıa unmortal véciò la parca, grandeza fingular, y atencion fabia,

Figura 6. Portada de la Verdadera relación de la coronación del Serenissimo Ivan Casimiro, príncipe de Polonia, por la mverte del poderosissimo rey Vladislao qvarto..

(CBDRS0005048)

Como se ha advertido hasta el momento, el interés por ciertas noticias hizo que fueran editados los mismos textos en imprentas o ciudades diferentes ${ }^{16}$. Ya se ha señalado, por ejemplo, el caso del monstruoso pescado, cuyo éxito editorial dio lugar a siete impresos. También las victorias dieron lugar a estas emisiones o nuevas 
ediciones, como es el caso de la victoria de Vladislao IV, rey de Polonia, en 1634. De esta noticia conocemos dos variantes: una impresa en Barcelona, por Pere Lacavallería, y otra sin datos ni de impresor ni de lugar de impresión.
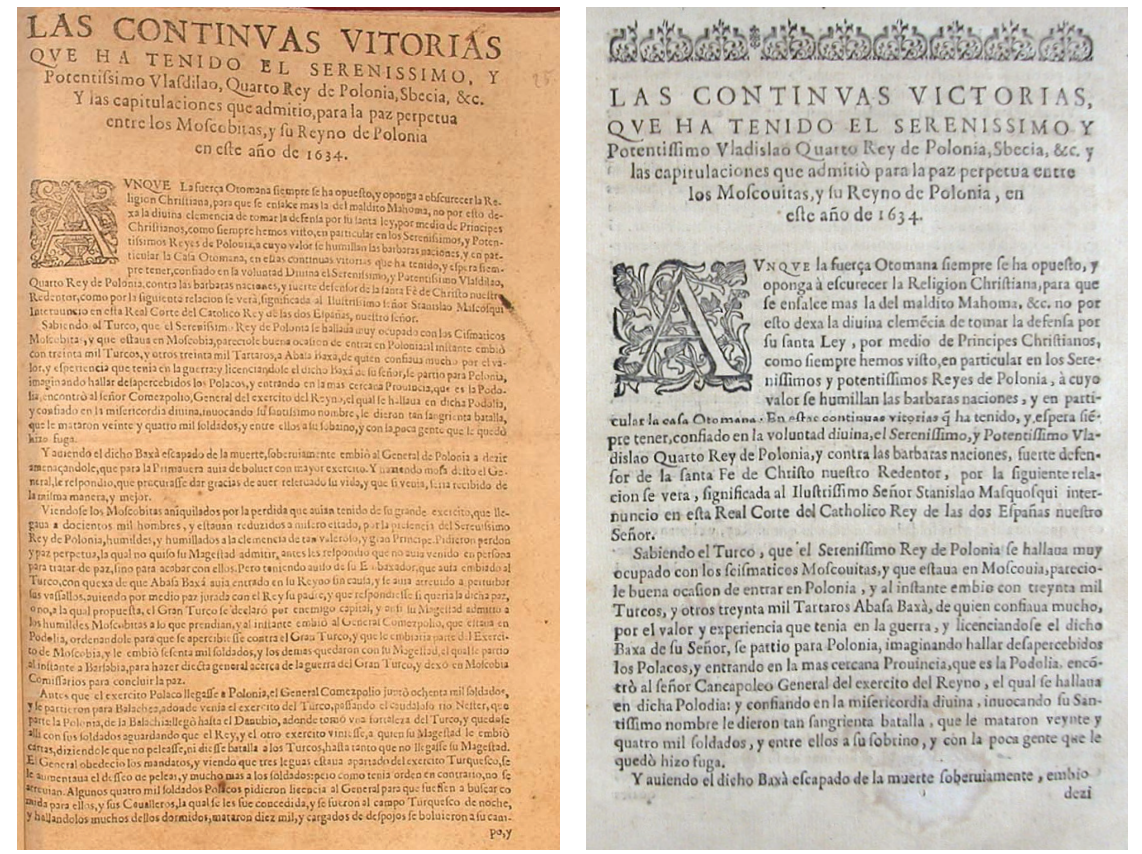

Figuras 7 y 8 . Portadas de Las continuas victorias... (CBDRS0001949A y B)

Esto evidencia, sin duda, la expectativa de éxito que anhelaba cualquier impresor o editor a la hora de sacar al mercado noticias relacionadas con Polonia. Como es lógico, sobre todo en torno a 1683, los relatos político-militares coparon la atención de aquellos promotores, aunque hemos comprobado que tampoco menospreciaron otras novedades (sucesos extraordinarios, milagros, fiestas, etc.) procedentes de una zona tan alejada del marco hispano. Sin embargo, este fenómeno de creciente interés por los avatares que tenían lugar en la Europa del Este debería ponerse en contexto, pues no solo afectó a la zona polaca, ya que recientemente Usunáriz Garayoa ${ }^{17}$ ha constatado que en las últimas décadas del siglo XVII también comenzaron a proliferar impresos sobre Moscovia. Es decir, la geopolítica tras el retroceso del Imperio Otomano estaba cambiando y había introducido en el tablero a dos nuevos agentes: polacos y rusos. Si bien es cierto que los primeros fueron considerados por la Monarquía Hispánica como un aliado natural en aquella parte del continente. 


\section{LOS AGENTES DE LA INFORMACIÓN: AUTORES, TRADUCTORES E IMPRESORES}

El saber quién escribió el texto noticiero resultaría de gran interés para conocer a fondo el proceso de gestación de las noticias, pero, lamentablemente, se explicita en contadas ocasiones. En el caso del conjunto que nos ocupa, debe señalarse que sigue la costumbre habitual en la publicación de los textos informativos: en su mayoría se publican como anónimas. Solo diez relaciones (catorce ediciones) indican de forma clara su autor. En ese caso, normalmente, son personajes ilustres o conocidos como Mathias Tylewski ${ }^{18}$, Benito de Sojo, Pedro Fernández Navarrete, Juan Bautista de Morales (Fig. 9, entrada 110), o el propio Juan III Sobieski, rey de Polonia (Fig. 10, entrada 43), de quien se da a la imprenta la copia de una carta con información histórico-política.

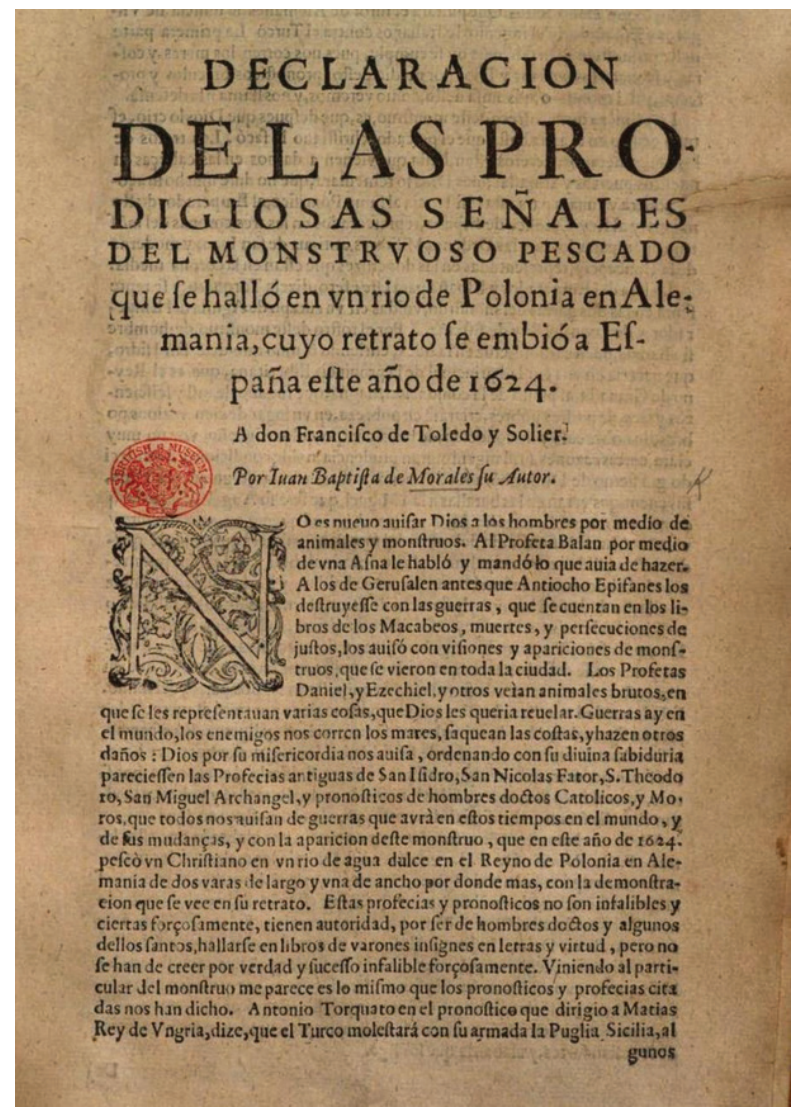

Figura 9. Portada de la Declaración... escrita por Juan Bautista de Morales (CBDRS0003473B)

18. El padre M. Tyelewski acompañó al embajador polaco en Madrid. Adam Mąkowski fue quien mandó traducir al español su relación, impresa en latín en Nápoles (Piłat Zuzanckiewicz, 2015, p. 299). La obra de Tyelewski, y sus tres ediciones (dos en latín y una en español) son piezas clave en la consideración de Polonia como baluarte de la fe y aliada de España en la defensa de la cristiandad. 
Aunque, por su propia naturaleza, como productos de mercado y por su finalidad misma, las noticias viajan y, por lo tanto, con frecuencia deben traducirse para publicarse en otras lenguas, no suele indicarse el nombre del traductor, pero no es extraño que se explique de dónde viene la noticia o que ha sido traducida. En ocasiones, se hace incluso especial hincapié en la legalidad de este traductor por la importancia de la materia que trata, como en la traducción de la carta del rey de Polonia a su esposa ${ }^{19}$.

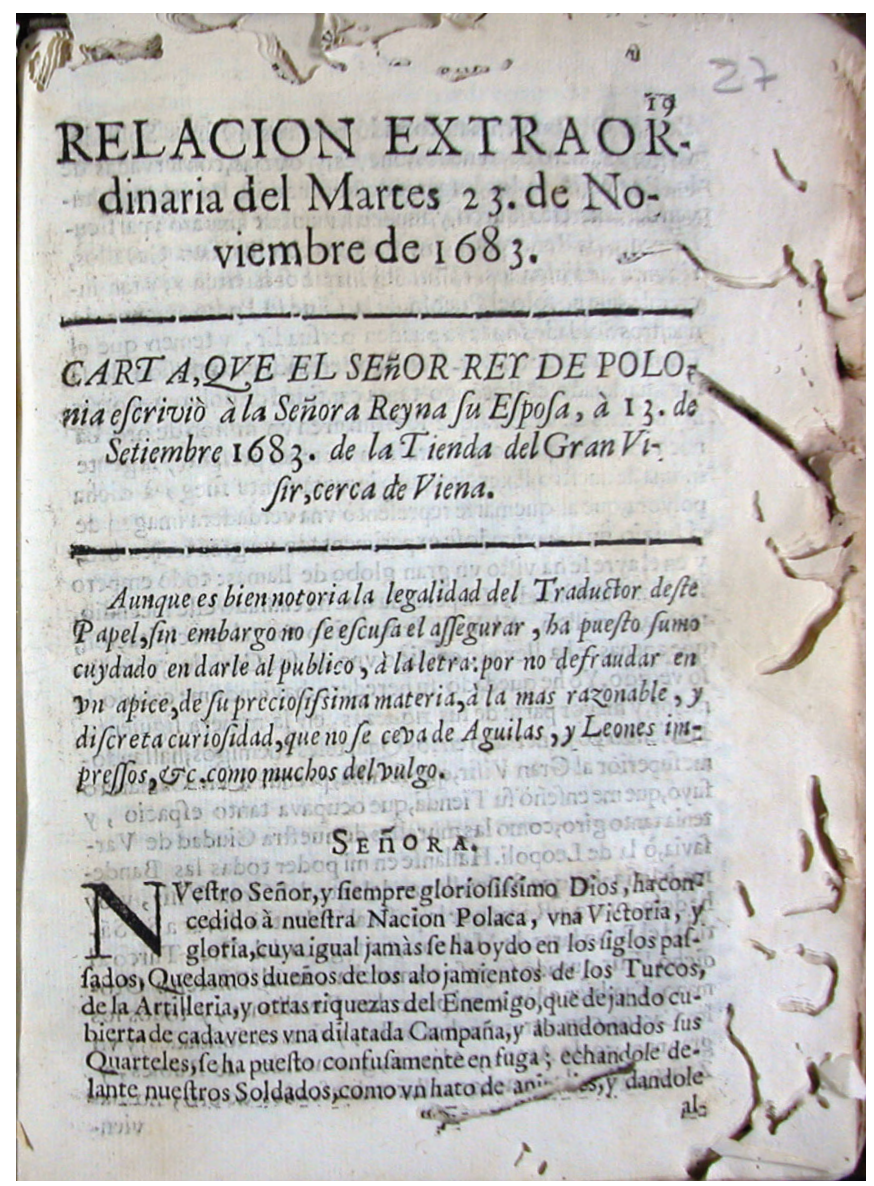

Figura 10. Portada de la carta del rey con nota sobre la traducción (CBDRS0000936)

19. El ánimo victorioso del rey puede traslucirse en sus palabras, pues comienza la carta: «Nuestro Señor y siempre gloriosísimo Dios ha concedido a nuestra Nación Polaca una victoria y gloria, cuya igual jamás se ha oído en los siglos pasados. Quedamos dueños de los alojamientos de los turcos, de la artillería, y otras riquezas del enemigo, que dejando cubierta de cadáveres una dilatada campaña y, abandonando sus cuarteles, se ha puesto confusamente en fuga». Y finaliza: «En fin, el enemigo queda deshecho, y con la fuga procura salvar la vida. Alégrese Vuestra Serenidad y dé gracias a Dios de que no haya permitido a estos infieles preguntar en chanza: “¿Adónde está el Dios de los cristianos?"» (entrada 43, CBDRS0000936). 
En el caso que nos ocupa, se indica con asiduidad que las noticias llegaron en los correos de Italia o del Norte ${ }^{20}$, y que han sido traducidas al castellano, normalmente del italiano, pero también del latín. Véase, por ejemplo, la Copia de Carta de un cauallero polaco, escrita a un hijo suyo en que le da noticia de lo sucedido entre el Rey de Polonia y sus senadores a cerca de la paz propuesta por los Turcos: impresa en Genova y Milan y traducida al castellano. Zaragoza, Herederos de Diego Dormer, [1684] (CBDRS0003251)21 o el ya visto Pronóstico y explicacion de las siete letras que se hallaron en el montrvo (Fig. 5), en donde se advierte: Traducida de lengua latina en castellana por el dotor don Gonzalo de Abarca, natural de Salamanca (CBDRS0006431).

Aquellas noticias posteriormente eran editadas en diversos talleres, aunque resulta muy llamativo comprobar que la inmensa mayoría de las relaciones de sucesos y noticias sobre Polonia están impresas en Madrid (67) ${ }^{22}$, algo lógico porque se trataba del centro de la Monarquía Hispánica. Sobresale así frente a otros centros impresores de la época como Sevilla (18) o Barcelona (11), que también eran centros editoriales de primer orden, así como destacados focos generadores de noticias de todo tipo. $Y$ en un tercer nivel incluso encontramos otros lugares de edición como Zaragoza y Valencia, en los que se registran muy pocas ediciones (2), superados incluso por Granada (3). Por último, y de manera casi testimonial, cabe mencionar que se encuentran relaciones impresas en Salamanca, Murcia o Montilla.

Gráfico 2. Comparativa de los lugares de impresión de las noticias en el siglo XVII

60

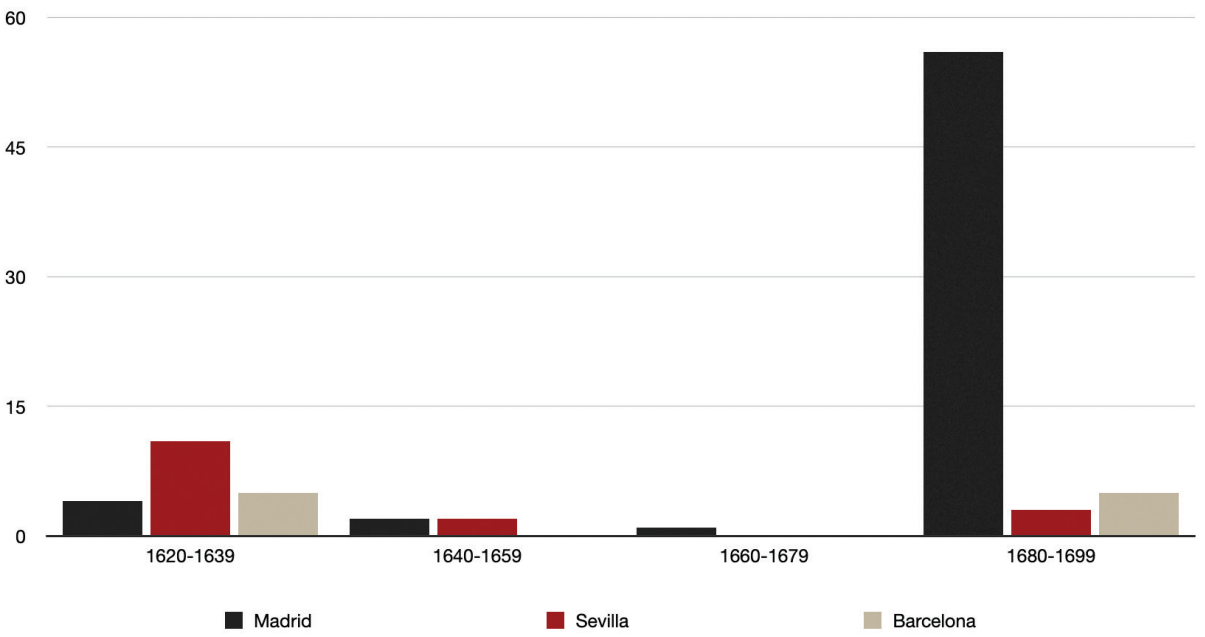

20. Sobre este tema pueden consultarse los trabajos de Infelise, 2010 y Bąk, 2001.

21. Véanse las entradas 5 y 6.

22. De estas 67 ediciones madrileñas, 19 incluyen la referencia explícita en el impreso mientras que se ha deducido la localización en las restantes 48 por sus características materiales y tipográficas. 
El peso de Madrid, sobre todo a finales del siglo XVII, no nos debe sorprender, pues algunas imprentas madrileñas ya aparecen asociadas a las publicaciones periódicas, como la de Sebastián de Amendáriz ${ }^{23}$ o la de Antonio Bizarrón ${ }^{24}$. Ambas fueron desde 1680 las más destacadas en la producción de noticias sobre Polonia, pero también debemos destacar otras muy conocidas de impresos menores como las sevillanas de Simón Fajardo ${ }^{25}$ o Juan Gómez de Blas² ${ }^{26}$, así como las barcelonesas de Joan Jolis ${ }^{27}$ y Esteban Liberós ${ }^{28}$, por citar los más representativos.

De esto se desprende que la edición de las noticias se repartió por buena parte de la geografía hispana, a lo que hay que sumar el hecho de que, pese a constatarse un interés generalizado a lo largo de toda la centuria, se evidencia que hubo momentos y acontecimientos que despertaron un mayor interés editorial, lo que se tradujo en un mayor número de impresos. Del análisis de las ediciones localizadas en el CBDRS inferimos que apenas hay publicaciones noticieras sobre el reino de Polonia hasta 1622, comenzando entonces un interés informativo propiciado por las guerras contra los turcos y la publicación de diversas relaciones relativas a la aparición del monstruo pescado en 1624 y 1625.

A partir de ahí, se mantuvo un interés moderado por los asuntos polacos. Será en 1683, con la creación de la Liga Santa contra los turcos y la llegada de Fabro Bremundán a España, cuando comience una actividad informativa realmente intensa, llegando a ser de publicación seriada y semanal, tanto en las publicaciones de Gacetas o nuevas periódicas como a través de relaciones de sucesos extraordinarias ${ }^{29}$. Bien es cierto que ese ritmo bajó considerablemente una vez terminada la guerra, quedando bajo mínimos en la centuria posterior, cuando solo se registran ocho ediciones.

23. Fue uno de los editores de relatos noticiosos más relevante de su época (en la década de los 80 del siglo XVII). Véase Delgado Casado, 1996, pp. 43-44.

24. Además de mercader y editor, también figura en algún pie de imprenta este madrileño de finales de siglo. Delgado Casado, 1996, pp. 71-72.

25. Destacado impresor y editor afincado en Sevilla, trabajó entre 1622 y 1650, con un creciente interés por publicar textos noticiosos venidos de toda Europa. Véase Delgado Casado, 1996, pp. 211-212.

26. Este sevillano trabajó más de tres décadas (entre 1633 y 1667) y de su taller salieron numerosas relaciones de sucesos, pliegos poéticos, etc. Delgado Casado, 1996, pp. 283-284.

27. En su taller de Barcelona tuvo una prolífica actividad entre 1679 y 1705, dando cabida a los relatos noticiosos entre sus impresos. Delgado Casado, 1996, pp. 348-349.

28. Se erigió en uno de los más activos impresores en la Barcelona de los años 1613-1633, prestando mucha atención a los sucesos de cualquier índole. Delgado Casado, 1996, pp. 385-386.

29. La década de los ochenta del siglo XVII fue especialmente atractiva para la circulación de aquellos productos editoriales, sobre todo relacionados con la lucha contra el turco. Véase Díaz Noci, 2008, p. 134. 


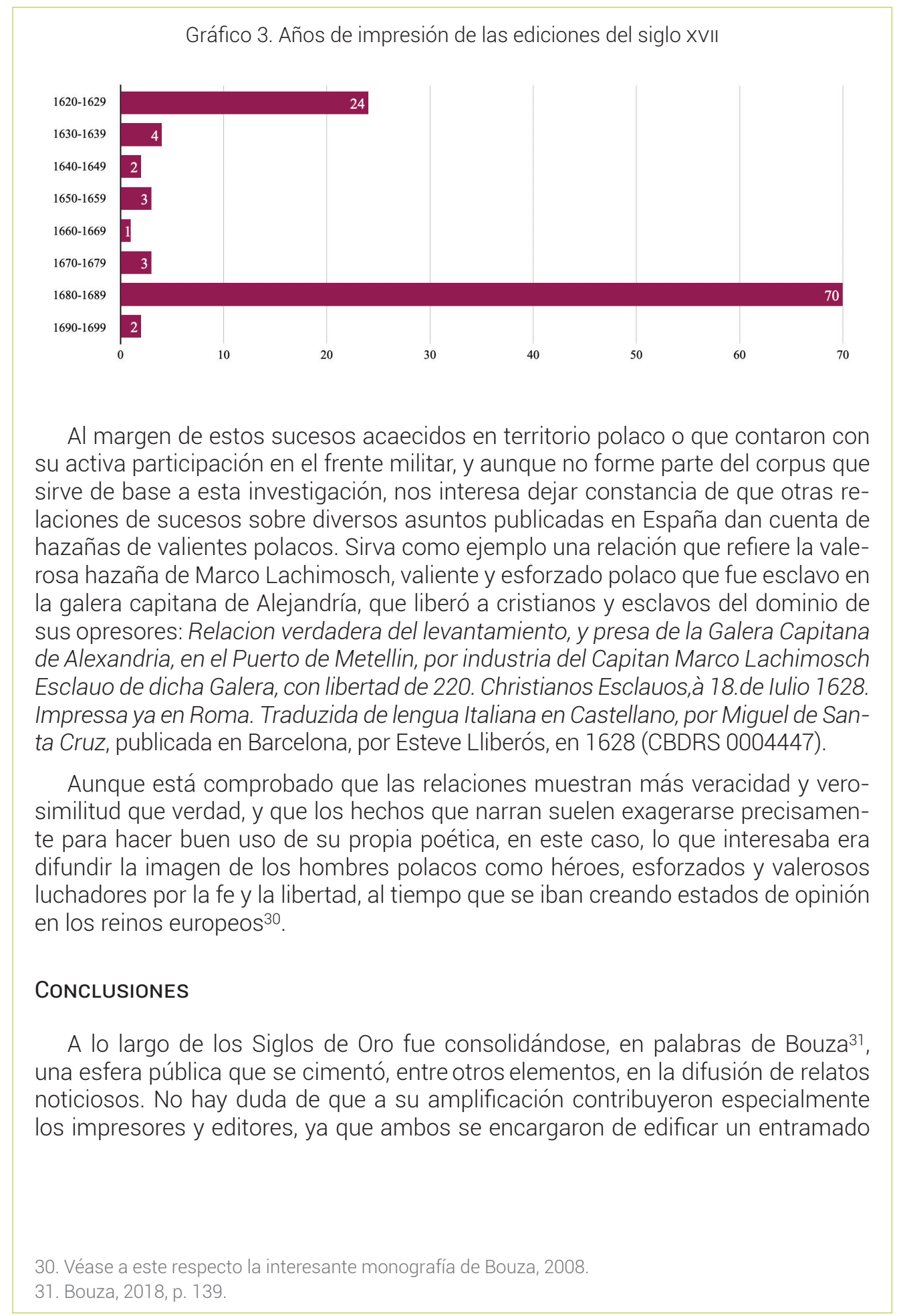


socio-cultural en el que las relaciones de sucesos y las gacetas - germen del posterior periodismo- se fueron convirtiendo en algo cotidiano. En aquel contexto no debe extrañarnos que circulasen a lo largo y ancho de la geografía hispana noticias impresas relativas a todo tipo de lugares, tanto próximos como lejanos.

Entre los espacios geográficos a los que se prestó una especial atención cabe destacar la actual Polonia. Así, gracias al análisis de los datos y el estudio detenido de un conjunto de publicaciones informativas de tema polaco, puede decirse que, por lo menos en el siglo XVII, las relaciones entre Polonia y España fueron bastante fluidas al tratarse de un aliado en el enfrentamiento contra el turco. Esto se trasluce del interés que despertaron las informaciones provenientes de tierras polacas, una zona que era la frontera natural con la Rusia de los Románov y el imperio otomano, por lo que actuó como cabeza visible de la Liga Santa creada en 1683. En definitiva, esa demanda de noticias vuelve a poner de manifiesto el fenómeno paneuropeo del que habló Ettinghausen ${ }^{32}$ sobre la circulación de textos informativos en el viejo continente.

Como se ha comprobado en el presente trabajo, generó tal interés el tema polaco que la publicación de impresos noticieros pasó de ser ocasional en la primera mitad del siglo XVII, a ser seriada (en fascículos - con numeración y signaturas tipográficas consecutivas - que incluso podían reunirse al final del año en un único tomo) y periódica. Esto hace pensar que aquellas noticias se consumían con cierta avidez en España gracias a la pericia de impresores y editores. De ahí que fruto de la gran cantidad de textos noticieros publicados y, sobre todo, de su contenido, pueda considerarse que el reino de Polonia fue un elemento importante en el juego político y diplomático de la Casa de Austria, constituyéndose así en el aliado perfecto para la defensa de los valores católicos en la Europa del Este.

En suma, gracias a los relatos noticiosos existentes sobre Polonia en el CBDRS se deja entrever el engranaje y funcionamiento de aquel entramado comercial en el que circularon y se intercambiaron las noticias con una clara finalidad mercantilista. Es decir, lo que acaecía en Polonia o sobre los polacos interesaba al público. De todas formas, calibrar aquel interés solamente es posible porque en la actualidad contamos con bases de datos y bibliotecas digitales que permiten almacenar gran cantidad de información y realizar análisis cuantitativos y cualitativos, resultado del estudio de una enorme cantidad de datos cruzados.

En este rico e impredecible horizonte que están tejiendo las Humanidades Digitales se presentan las relaciones entre España y Polonia, como un tema que merece un estudio mayor que permita conocer los intereses que se gestaron entre ambas monarquías y, además, reconstruir las redes comunicativas en la Europa de la Edad Moderna. Solo así conseguiremos descubrir sucesos, lugares y personas que actuaron como nodos de información y autores o traductores que se prestaron a contar (celebrar, reinventar, exagerar, etc.) los hechos acontecidos, pues tanto el 
número de los datos como la profundidad del análisis demuestran la profesionalidad de los autores de aquellos textos. Esto vislumbra, además, que Polonia y otros reinos de la Europa central y septentrional de aquel entonces no se encontraban tan alejados ni cultural ni políticamente hablando de los intereses de la Monarquía Hispánica.

\section{BiBLIOGRAFÍA}

Baczyńska, Beata, Dramaturg w wielkim teatrze historii. Pedro Calderón de la Barca, Wrocław, Wydawnictwo Uniwersytetu Wrocławskiego, 2005.

Bąk, Grzegorz, «Noticias del Norte: la Polonia de los años 1683-1703 en las páginas de la prensa española de la época», Eslavística Complutense, 1, 2001, pp. 371-380.

Biliński, Bronislaw, «Memorabile impresa di Marco Jakimowski 220 schiavi cristiani liberati e portati a Roma nel 1628», en Figure e momenti polacchi a Roma. Strenna di commiato, Wrocław, Zakład Narodowy im. Ossolińskich, 1992, pp. 315-327.

Bouza, Fernando, Papeles y opinión. Políticas de publicación en el Siglo de Oro, Madrid, CSIC, 2008.

Bouza, Fernando, «El pueblo desea las noticias. Relaciones de sucesos y gacetas entre propaganda y esfera pública en la España de los Austrias», Hemeroteca Municipal de Madrid, 1, 2018, pp. 111-143.

CBDRS, Catálogo y Biblioteca Digital de Relaciones de Sucesos, BIDISO (Biblioteca Digital Siglo de Oro) [en línea], http://www.bidiso.es/CBDRS, ISSN 2697-0309 [fecha de consulta: 14/12/2020]

Carabias Torres, Ana María, «La producción editorial sobre el Imperio otomano y los turcos en España (1470-1850). Una investigación in fieri», Tiempos Modernos. Revista Electrónica de Historia Moderna, 7-20, 2010, pp. 1-35.

Conde Pazos, Miguel, «Entre franceses y españoles: el Cardenalato del príncipe Juan Casimiro Vasa y la diplomacia hispano italiana en Italia (1643-1648)», Libros de la Corte.es, núm. Extra 1, 2014, pp. 33-51.

Delgado Casado, Juan, Diccionario de impresores españoles (siglos XV-XVII), Madrid, Arco Libro, 1996, vol. I.

Díaz Noci, Javier, «El Mediterráneo en guerra. Relaciones y gacetas españolas sobre la guerra contra los turcos en la década de 1680», en España y el mundo mediterráneo a través de las Relaciones de Sucesos, coord. Pierre Civil, Françoise Cremoux y Jacobo Sanz, Salamanca, Universidad de Salamanca, 2008, pp. 131-140. 
Eminowicz, Teresa, «La imagen de España en Polonia en los siglos XVI y XVII», en Imágenes de España en culturas y literaturas europeas (siglos XVI-XVIII), ed. José Manuel López Abadía y Augusta López Bernasocchi, Madrid, Verbum, 2004, pp. 177-196.

Ettinghausen, Henry, Noticias del siglo XVII: relaciones españolas de sucesos naturales y sobrenaturales, Barcelona, Puvill, 1995.

Ettinghausen, Henry, «Relaciones internacionales las relaciones de sucesos, un fenómeno paneuropeo», en Las relaciones de sucesos en los cambios políticos y sociales de la Europa Moderna, coord. por Jorge García López y Sònia Boadas, Girona, Universitat de Girona, 2015, pp. 13-27.

Infelise, Mario, «El mercado de las noticias en el siglo XVII: las tipologías de la información», en Opinión pública y espacio urbano en la Edad Moderna, coord. Antonio Castillo Gómez y James S. Amelang, Gijón, Trea, 2010, pp. 153-162.

López Poza, Sagrario, «Humanidades digitales y literaturas hispánicas: presente y futuro», Ínsula, 822, 2015, pp. 3-5.

Mancera Rueda, Ana, y Galbarro García, Jaime, Las relaciones de sucesos sobre seres monstruosos durante los reinados de Felipe III y Felipe IV (1598-7665). Análisis discursivo y edición, Bern / Berlin / Bruxelles / Frankfurt am Main / New York / Oxford / Wien, Peter Lang, 2015.

Pena Sueiro, Nieves, «El portal BIDISO: pasado, presente y futuro inmediato. Un ejemplo de evolución en las aplicaciones de HD», Studia Aurea. Revista de Literatura Española y Teoría Literaria del Renacimiento y Siglo de Oro, 1, 2017, pp. 73-92.

Pena Sueiro, Nieves, y Álvarez García, Sandra, «Recursos digitales para la investigación en literatura española: la Biblioteca Digital Siglo de Oro», en Cincuentenario de la Asociación Internacional de Hispanistas, A Coruña, Universidade da Coruña, 2014, pp. 381-391.

Pena Sueiro, Nieves, y Saavedra Places, Ángeles, «Obsolescencia y resiliencia en Humanidades Digitales. El caso de la Biblioteca Digital de Relaciones de Sucesos», Artnodes, 23, 2019, pp. 79-88.

Piłat Zuzankiewicz, Marta, «La elección y coronación de Juan Casimiro Vasa, rey de Polonia, en las relaciones de sucesos españolas», en Las relaciones de sucesos en los cambios políticos y sociales de la Europa Moderna, ed. Jorge García López y Sònia Boadas, Bellaterra, Universitat Autònoma de Barcelona, Studia Aurea Monográfica, 6, 2015, pp. 297-308.

Río Parra, Elena del, Una era de monstruos. Representaciones de lo deforme en el Siglo de Oro español, Madrid / Frankfurt am Main, Iberoamericana / Vervuert, 2003.

Skowron, Ryszard, Olivares, los Vasa y el Báltico. Polonia en la política internacional de España en los años 1621-1632, Varsovia, DiG, 2008. 
Skowron, Ryszard, «Cuda i bitwy w relacjach Benita Soxa. Trzy hiszpańskie druki ulotne z okresu wojny polsko-szwedzkiej w Prusach (1626-1629)», en Sic erat in votis. Studia i szkice ofiarowane Profesorowi Zbigniewowi Anusikowi, ed. Małgorzaty Karkochy i Piotra Robaka, t. 2, Łódź, Wydawnictwo Uniwerytetu Lodzkiego, 2017, pp. 141-155.

Taracha, Cezary (coord.), We wspólnej Europie. Polska-Hiszpania, XVI-XX wiek: referaty wygloszone podczas sympozjów historyków polskich i hiszpanskich w Lublinie i Logroño, 1999-2000, Lublin, Katolicki Uniwersytet Lubelski = Catholic University of Lublin, KUL, 2001.

Tropé, Hélène, «Propaganda y profecía en la España de los siglos XVI y XVII: las relaciones de sucesos referidas a monstruos», eHumanista. Journal of Iberian Studies, 36, 2017, pp. 116-126.

Urjasz-Raczko, Matylda, «La estrategia diplomática de Felipe II frente a la Tercera Elección Libre en La República Polaco-Lituana, 1586-1589», Studia historica. Historia moderna (Ejemplar dedicado a Duelo entre colosos: el Imperio Otomano y los Habsburgos en el siglo XVI), 36, 2014, pp. 213-232.

Usunáriz Garayoa, Jesús M., "Muscovy in the Golden Age in Spain: Chronicles and News Pamphlets», Hipogrifo. Revista de literatura y cultura del Siglo de Oro, volumen extraordinario, 1, 2018, pp. 141-160. DOl: https://doi. org/10.13035/H.2018.extra01.10.

Usunáriz Garayoa, Jesús M., España en Alemania: la guerra de los Treinta años en las crónicas y relaciones de sucesos, New York, IDEA (Instituto de Estudios Auriseculares), 2016, http://hdl.handle.net/10171/41828.

Zawadzkin, Konrad, Gazety ulotne polskie i Polski dotyczące XVI-XVIII wieku: bibliografía, Polska Akademia Nauk. Instytut Badań Literackich, Wrocław, Zakł. Nar. im. Ossolińskich, 1997-1990, 3 tomos. 


\section{APÉNDICE}

El corpus ${ }^{33}$ contiene las 119 ediciones de relaciones de sucesos y otros impresos noticieros sobre Polonia existentes en el CBDRS [fecha de consulta: 20/12/2020]:

1. AVISO CIERTO, I Y /RELACION / VERDADERAI DE LAS ARMAS /IMPERIALES. LCONTRA I EL OTHOMANO / IMPERIO. [Barcelona], [1687]. CBDRS0004963.

2. Avisos ciertos, y verdaderos, de los svcessos de las gverras, y de la Liga Catolica, que se ha jurado delante de su Santidad, por el Señor Emperador, el Rey de Polonia, y Venecia, contra el Turco, à veinte y quatro de Mayo de este presente año de mil seiscientos y ochenta y quatro. Barcelona, Jacint Andreu, [1684]. CBDRS0004792.

3. Carta nveva del mas prodigioso svcesso que se ha visto, y monstruosidad de hombre que se ha hallado: Sucedido en el Reyno de Polonia. Barcelona, Josep Forcada 1674. CBDRS0004976.

4. Carta que escrivio al Rey nuestro Señor Carlos II. (que Dios guarde) el Señor Rey de Polonia Ivan III. desde el Castillo de Strigonia à veinte y ocho de Octubre 1683. Tradvcida de la lengva Latina, y ofrecida en la Relacion de 28. de Diziembre del presente 1683. [Madrid], Sebastián de Armendáriz, 1683. CBDRS0005116.

5. Copia de Carta de un cauallero polaco, escrita a un hijo suyo en que le da noticia de lo sucedido entre el Rey de Polonia y sus senadores a cerca de la paz propuesta por los Turcos : impresa en Genova y Milan y traducida al castellano. Barcelona, Joan Jolis, [1684]. CBDRS0003251A.

6. Copia de Carta de un cauallero polaco, escrita a un hijo suyo en que le da noticia de lo sucedido entre el Rey de Polonia y sus senadores a cerca de la paz propuesta por los Turcos : impresa en Genova y Milan y traducida al castellano. Zaragoza, Herederos de Diego Dormer, [1684]. CBDRS0003251B.

7. Copia de la declaracion hecha en nombre del Rey Christianissimo en el mes de Marzo de 1733. Declaracion de el Emperador, en respvesta de la de el Rey Christianissimo. Copia de la declaracion del Emperador, y de sus Aliados. Carta de el Rey Christianissimo, al Primado, de 6. de Iulio de 1733. Barcelona, Josep Teixidor, [1733]. CBDRS0005201.

33. El corpus que aquí se presenta es de finales de 2020, pero la digitalización masiva de bibliotecas nos ha permitido descubrir ediciones o ejemplares nuevos a diario, especialmente sobre la guerra contra los turcos (sobre todo noticias seriadas de Armendáriz a partir de 1683), pero dado que antes precisan de un proceso de análisis y volcado en el CBDRS no han podido ser incluidas en este trabajo, por lo que se tendrán en cuenta en estudios posteriores. 
8. De la Gazeta Unibersal de Venecia. Varsovia $7^{\circ}$ de Abril. Copia de la Carta del Conde Stadelberg, Embajador de Prucia en esta Corte à monseñor Archetai Nun. Apco. S. I., [s. a.]. CBDRS0004145.

9. Gaceta general de Evropa, Assia, y America. Y vna exortacion eloqvente, y fervorosa con qve animo a pelear a svs Ivcidas tropas, y esforzados soldados el invictissimo Rey de Polonia. Madrid 13 de Diziembre de 1683. Con licencia. En Madrid, en la Imprenta Real: A la Calle del Carmen: Por Mateo de Llanos. Año 7683. Hallarase en la Puerta del Sol en casa de luan Martin Merinero, Librero, y en Palacio. Madrid, Mateo de Llanos e Imprenta Real [Juan Martín Merinero], 1683. CBDRS0001319.

10. Gazeta de Lisboa Occidental. Com Privilegio de S. Magestade. Quinta feira 18. de Janeiro de 1725. S. I., [1725]. CBDRS0003621.

11. GAZETA DE MADRID DEL MARTES 18 DE AGOSTO DE 1789. Madrid, Imprenta Real, 1789. CBDRS0004235.

12. GAZETA DE MADRID DEL MARTES 28 DE MAYO DE 1793. Madrid, Imprenta Real, 1793. CBDRS0004236.

13. GAZETA DE MADRID DEL VIERNES 18 DE ABRIL DE 1794 . Madrid, Imprenta Real, 1794. CBDRS0004237.

14. La ley del Talion executada en los incendiarios, tartaros, crimenses, y precopenses. Relacion puntual, sincera, y erudita traducida de la lengua latina de los sucessos prodigiosos, que en beneficio de la Christiandad, y de la corona de Polonia, han conseguido los cosacos, y moldavos en la V Kraina, y tartarias, assistidos de la autoridad del señor rey, y republica de Polonia, y con especialidad de las pijssimas, y zelantissimas liberalidades de nuestro santissimo padre Innocencio XI, debajo de su general Kuniki, vigilantissimo, valerosissimo, y felicissimo como assimesmo el castellano de cracovia con los polacos, y cosacos de su mando en la provincia de Podolia. Advertencia y aviso caritativo a otros incendarios, imitadores fatales de essotros, tan exemplarmente escarmentados. [Madrid], Antonio Román-Sebastián de Armendáriz, 1684. CBDRS0001424.

15. LAS CONTINVAS VITORIAS QVE HA TENIDO EL SERENISSIMO, Y Potentissimo Vlasdilao, Quarto Rey de Polonia, Sbecia, \&c. Y las capitulaciones que admitio, para la paz perpetua entre los Moscobitas, y su Reyno de Polonia en este año de 1634. S. I, [s. i.], 1634. CBDRS 0001949A. 
16. LAS CONTINVAS VITORIAS QVE HA TENIDO EL SERENISSIMO, Y Potentissimo Vlasdilao, Quarto Rey de Polonia, Sbecia, \&c. Y las capitulaciones que admitio, para la paz perpetua entre los Moscobitas, y su Reyno de Polonia en este año de 1634. Barcelona, Pere Lacavalleria, 1634. CBDRS 0001949B.

17. Noticia al embaxador del rey catholico en la corte britanica, de las razones que han obligado a su magestad a hacer la guerra al emperador. Se hallarà en casa de Manuel Ignacio de Pinto, Mercader de Libros en la Calle de Atocho, junto à la Aduana. S. I., Manuel Ignacio de Pinto, [1733]. CBDRS0001487.

18. Noticias extraordinarias, de las cosas y desposiciones actuales de las Cortes de Polonia, y Turquia, traducidas de una Carta escrita de la Ciudad de laroslavia (que es del Reyno de Polonia en la Rusia Negra) à 10. de Março 7684. S. I., Sebastián de Armendáriz, 1684. CBDRS0001520.

19. Noticias extraordinarias, y singvlares, del estado presente de la Europa. Madrid, Antonio Bizarrón, 1701. CBDRS0004163.

20. Noticias Generales de Europa, que llegaron á Zaragoza con el Correo de Flandes el dia 29. de Setiembre, y con el de Italia el dia 30. S. I., [1650]. CBDRS0003610.

21. Noticias generales de Evropa, y particulares de la Conquista de Napoles de Romania por las Armas Venecianas, venidas à Barcelona por el Correo de Flandes à 18. de Octubre. Y va al vltimo vna Carta escrita del Baxà de Buda, al Serenissimo Señor Duque de Lorena. Barcelona, J. Matevat-Jaume Cays, 1686. CBDRS0004870.

22. Noticias generales de las cosas de Evropa, segun vinieron con los vitimos Correos del Norte, è Italia el Miercoles, y Jueves 25. y 26. de Mayo, y se publican el Martes 37. del propio mes 1689. Varsovia de 2. asta 15 de Abril 7689. Madrid, Antonio Román-Sebastián de Armendáriz, 1689. CBDRS 0001526.

23. Noticias generales de las cosas de Evropa, segun vinieron con los vitimos Correos, y se publican el Martes 12. de Julio 1689. Del Norte. Varsovia à 21. de Mayo 1689. [Madrid], [Antonio Román]-Sebastián de Armendáriz, 1689. CBDRS 0001527.

24. Noticias generales de las cosas de Evropa, segun vinieron con los vitimos Correos, y se publican en Martes 14 de Junio 1689. [Madrid], Sebastián de Armendáriz, 1689. CBDRS0001528. 
25. Noticias generales, venidas con el correo de Flandes de diferentes partes, $y$ como esta ya rendida la Gran Ciudad de Buda, Metropoli de toda la Vngria. [S. I.], [s. i.], [1686]. CBDRS0004755.

26. Noticias ordinarias Del Norte, Italia, España, y otras partes, publicadas el Lunes 20. de Septiembre de 1694. Madrid, Vicente de Armendáriz, [1698]. CBDRS0003620.

27. Noticias ordinarias Del Norte, y otras partes, con la Relacion especial de la Vitoria, que las Armas Imperiales, debaxo del mando del Señor Principe Luis de Baden, han reportado del Exercito Turco, y Tartaro, al retirarse los Barbaros de la Transilvania. Publicadas el Martes 20. de Febrero de 1697. Madrid, Antonio Román-Sebastián de Armendáriz, 1691. CBDRS0001543.

28. NOTICIAS PARTICULARES DEL ESTADO PRESENTE DE LA EUROPA. PUblicadas el martes 12 de julio de 1701. Madrid, Antonio Bizarrón, 1701. CBDRS0004027.

29. Noticias veridicas, y svcinto compendio de todos los felizes Progressos de las Armas Imperiales, y Polacas contra el Turco, desde el dia 3. de Octubre de 1683 hasta 3 de Noviembre de dicho Año. Qvatro gracias que sv santidad ha concedido al señor Rey de Polonia, despues de socorrida Viena. Ricos presentes qve el señor emperador, y à la Magestad Polaca embiò el Gran Duque de Toscana, con el Parabien de la Gran Vitoria conseguida contra el Turco. Toma, qvema, y demolicion de la plaza de Barkam, y de vn Puente que estava sobre el mismo Rio. Sitio de Estrigonia, assistido del señor Duque de Lorena, y Empressas intermedias del señor Rey de Polonia. VItima derrota que dieron los litvanos, y Polacos al Rebelde Conde Tekelli, con perdida de todos sus Bagages, Artilleria, municiones, y pertrechos: Con otras particularidades. [Madrid], Lucas Antonio de Bedmar y Baldivia, 1683. CBDRS0001601.

30. Nuevo, y Segundo Triunfo de la Religion Catolica, y Diario tocante al estado, sucessos, y progressos de la Liga Sagrada contra los Turcos, formado de las ultimas cartas de Italia, y el Norte. Sevilla, Thomas López de Haro, 1687. CBDRS0003613.

31. Nvevas ordinarias de los Sucessos de Norte. Publicadas el Martes 16 de Nouiembre 1683. Continuacion de los Progresos de los Exercitos de la Liga Sagrada, contra los Infieles. Peligro notable que corriò el Rey de Polonia. Cartas, con que S. Magestad Polaca participó la Victoria de Viena al Papa, al Dux 
de Venecia, y al Marques de Grana, Gouernador, y Capitan General de los Payses Baxos, \& c. Viena, à 9 y Lintz, à 12 y 13 de Octubre. [S. I.], Bernardo de Villadiego, 1683. CBDRS 0001537.

32. Nvevas singvlares concernientes a la Gverra Sagrada contra Turcos, segun las trajo el Correo del Norte, en cartas inmediatas de las Cortes Imperial, y Polaca. Publicadas el Martes 13. de lunio 1684. juntamente con las noticias diarias de los sucessos mas memorables de Europa. Llegada del Principe de Montecuculi, Embiado Extraordinario del Rey Nuesto señor (que Dios guarde) al Señor Rey de Polonia. Conclusion, y resulta cierta del Congreso de Kadzin. Tiempo fijo en que Su Magestad Polaca determinava hallarse personalmente en la empresa de Kameniez. Esfuerzos de los Turcos para restaurar debajo de su Proteccion al Principado de Valdaquia. Disposiciones del Señor Rey de Polonia para estorvarselo. Consequencias que produciràn su logro. Avisos de Turquia que se tenian en la Corte de Polonia. Aprestos de los Turcos para intentar el socorro de Neuheusel, y de los Imperiales para impedirle. Prorrogacion del termino antes publicado, al movimiento general, y operaciones de los Cesareos. Tekeli siempre obstinado. Proposiciones quimericas de su Embiado en medio de su orgullo. [Madrid], Antonio Román-Sebastián de Armendáriz, 1684. CBDRS 0001571.

33. Nvevas singvlares del Norte, y especialmente de los sucessos de Vngria, justificadas con Instrumentos del mas incontrastable credito. Publicadas à 14. de Diziembre 1683. Insinuacion precisa, à los demasiado credulos en materia de novedades. Carta con que el Señor Duque de Lorena participò à Su Magestad Cesarea lo occurido en el Assedio,ataque,y reducion de la Ciudadela de Strigonia. Capitulacion que S.A. concediò à los Turcos militares, y naturales de la mesma Ciudad. Otras noticias pertenecientes al propio sucesso, y otros consecutivos. Copia de la Carta, que escriviò la Señora Reyna Christina Alexandra de Suecia, al Señor Rey de Polonia, digna de esculpirse en Bronze, como lo son las Memorias de la Persona,y Virtudes de su Autora, de los Monumentos mas durables de la Fama. [Madrid], Bernardo de Villadiego - Sebastián de Armendáriz, [1683]. CBDRS0005113.

34. Nvevas singvlares del Norte, y otras partes de Europa. Publicadas el Martes 4. de Enero 1684. Disposiciones para la Liga contra Turcos. Recivimiento hecho al Duque de Baviera en su Corte de Monaco. Apuntamiento tocante à los solevados contra Turcos. Retrato en pequeño del Gran Visir, Kara Mustafà, muerto, ó vivo que sea. Suspension del ajuste de Tekeli, y en que estriva. No- 
ticias de Polonia importantes al avio de mayores empresas. Elogio excelente hecho en Latin,à los Cabos principales que han contribuido à las vitorias obtenidas contra los Infieles, y traducido en Romance. [Madrid], Sebastián de Armendáriz, 1684. CBDRS0005117.

35. PRONOSTICO/Y EXPLICACION I DE LAS SIETE LETRAS / QVE SE HALLARON EN EL MONTRVO / que aparecio cerca de la ciudad de Varuasia, en el Reyno I de Polonia: y relacion breue de otro monstruo que / a los 4. del mes de Mayo del presente año / ha aparecido muy cerca de di- I cha Ciudad. I Traduzida de lengua Latina en Castellana por el Dotor don Gon- I zalo de Abarca natural de Salamanca. I [grab. de carro de Saturno]. I CON LICENCIA DEL ORDINARIO.I En Barcelona en cas ade Sebastián y layme Matevad I Ano M.DC.XXIV. Barcelona, Sebastián y layme Matevad, 1624. CBDRS0006431.

36. Relación cuarta y carta verdadera enviada de la villa de Bruselas, en que se declara como el cristianísimo rey de Francia, teniendo preso al príncipe de Polonia, lo soltó y el gran recibimiento que le hizo su Alteza el señor infante cardenal. Y asimismo se declara la rota que los ejércitos imperiales dieron a las tropas de Yveimar y Longavila, con lo demás sucedido en los meses de abril y mayo de 1640. Madrid, Juan Sánchez, 1640. CBDRS 0006356.

37. Relación de la batalla que los ejércitos de su majestad cesárea y del rey de Polonia tuvieron con el de Suecia, su huida, rota y destrucción de toda su gente: en la cual los imperiales y polacos le mataron tres mil hombres, prendieron trescientos y ganaron once cornetas, y diez piezas de artillería con toda la munición y bagaje. Murcia, Luis Beros, 1629. CBDRS 0006313.

38. RELACION / DE LA SVNTVOSA ENTRADA / debaxo de palio enla villa de Madrid, del / Rey nuestro Señor Don Felipe quarto / que Dios guarde. / Refierese la forma del Real acompañamiento, libreas y otras / cosas grandiosas de aquel dia. I Cosas notables que ha hecho su Magestad, y oficios que ha dado / a diferentes Titulos y señores en estos dias. I Notables sucessos en Roma, y cosas memorables que su Sanctidad ha / hecho enel principio de su Pontificado,y famosa victoria que tuuo con / tra Turcos y Tartaros el Rey de Polonia,y castigo que se / dio al que le quiso matar en su Palacio. Seuilla, Iuan Serrano de Vargas y Vreña, 1621. CBDRS 0002742.

39. Relacion de las vitimas noticias que han venido a esta corte de todo lo sucedido à los Exercitos de los Señores Emperador, Rey de Polonia, y Principes Coligados co[n]tra las Armas Otomanas, desde el Socorro, y Batalha de Vieua [sic], hasta la Toma, y Rendimiento de la Ciudad de Estrigonia, vna de 
las principales, y fuertes Plazas del Reyno de Vngria, sobre el Dio Danubio. [Grab.] Con Licencia de los Señores del Consejo Real. En Madrid, en la Imprenta Real: A la calle del Carmen: Por Mateo de Llanos; Impressor del Rey N. S. año 1683. Vendese en la Puerta del Sol, en casa de luan Martin Merinero, y en Palacio, en los Caxones de Manuel del Campo, y luan de Calatayud, Libreros. Madrid, Imprenta Real, Mateo de Llanos-Juan Martín Merinero, 1683. CBDRS 0000874.

40. Relacion de los felices sucessos que ha tenido la Magestad de Vladislao Quarto, Rey de Polonia, y las pazes que ha hecho con el gran Turco, las capitulaciones dellas, las plaças que le entregaron, y las embaxadas que para ello se embiaron ... Valencia, Silvestre Esparsa, 1635. CBDRS0001181.

41. Relacion de los principales svcessos de los Tvrcos en Vngria, hasta este año de 85 en el qual assaltan à labarino, aviendo penetrado en los Paises Cesáreos, por traicion de los Rebeldes Vngaros. Sitian à Viena, corte de Austria. Retira se de ella el Sr. Emperador. Diferentes victorias, que, durante el Sitio, alcançò de Turcos, y Rebeldes, el señor Duque Carlos de Lorena. Llega el Señor Rey de Polonia co sus Tropas, y juntos ambos derrotan en campal batalla à Kara Mustafa, Primer Visir, y General de Mahomet Quarto, Gran Turco. Descripcion de la circunvalacion de Viena. Horrible estrago de los Enemigos. Y gran presa de los Christianos. Bvelven estos a la Vngria svperior. Passan à arrassar à Barkan. Peligro de los Señores Rey, y Príncipe de Polonia. Segunda Batalla, y rota de los Turcos. Toma de Barkan. Sitio y expugnacion de Estrigonia, por la Alteza de Lorena. Toma de Pest, por el señor Rey de Polonia, con las distancias, parages de todos los Lugares exactamente explicados. Cartas de los Señores Rey, y Dvque. Embaxada del rey al Papa, con el Estandarte del Turco. Demonstraciones agradecidas de su Santidad con la Nación Polaca. Varias Noticias del Rebelde Tekeli, con otras circunstancias recogidas de diferentes Relaciones, y Cartas que han Ilegado de Alemania, Flandes, y Italia. Vendese en Casa de Lucas Perez, enfrente de la Compañia de lesus. Salamanca, Lucas Pérez, 1685. CBDRS 0000836.

42. RELACION EN OVE SE DA OVENTA DE LAS GRANDIOSAS PRESAS que IOS Navios de Dumquerque (de los Estados que govierna la Serenissima Infanta doña Isabel de la Paz) traen cada dia a fus Puertos. Y la feliz vitoria que el Rey de Polonia à tenido con los Tartaros y Trasilvanos, en que les mataron mas de sesenta mil hobres y quitadoles muchos despojos de importancia. Año de 1626. Sevilla, Juan de Cabrera, 1626. CBDRS 0005464. 
43. Relacion extraordinaria del Martes 23 de Noviembre de 1683. Carta, que el señor Rey de Polonia escriviò a la Señora Reyna su Esposa, à 73. de Setiembre 1683. de la Tienda del Gran Visir, cerca de Viena. [S. I.], Bernardo de Villadiego, 1683. CBDRS 0000936.

44. Relacion historial de las invasiones que el Rey de Suecia, los Moscovitas, y Cosacos han hecho en el Reyno de Polonia, hasta desposseer de aquel Reyno a Juan Casimiro su legitimo Rey y señor: y las causas que tuvieron para esto. Y como el Rey de Polonia, con el socorro de dinero que ha tenido del Pontifice, vâ recuperando sus Estados con grande felicidad, y destroço del Rey de Suecia. Este año de 1656. Sevilla, Juan Gómez de Blas, 1656. CBDRS0003870.

45. Relacion Historica Del año 1686. Tocante al estado svcessos, y progressos de la Liga Sagrada contra Tvrcos. Formada de las cartas del Norte. Publicada el Martes 23. de Iulio. Nuevas de Polonia de muy buen semblante. Marchas del Exercito Imperial, y principios del Assedio de Buda, sabido con Extraordinario de Italia y cartas de Viena de 23. de lunio. Vitoria insigne de las Armas de la Serenissima Republica de Venecia, con la Toma de la afamada Fortaleza de Navarino, Viejo y Nvevo y de su afamado Puerto. [Madrid], Antonio Román-Sebastián de Armendáriz, [1686]. CBDRS0004957.

46. Relacion historica Del año 1686. Tocante al estado, successos, y progressos de la Liga Sagrada contra Tvrcos. Formada de las ultimas cartas de el Norte, è Italia. Publicada el Martes 13. de Agosto. Salida à Campaña de los Exercitos de Polonia, y Moscovia. Resolucion Magnanima de los Principes de Balaquia, y Moldavia. Continuase el Diario de las operaciones de los Imperiales sobre Buda. Proezas particulares de la Nobleza Española sobre aquella Plaza. Estado al parecer bien adelantado, y con buenas esperanças de aquel Assedio. Enmienda inescusable de la Relacion errada, que en falta de otra se publicò en la Relacion antecedente de la Conquista de Naudrin. [Madrid], Antonio Román-Sebastián de Armendáriz, 1686. CBDRS0000972.

47. Relacion Historica Del año 1686. Tocante al Estado, Sucessos, y Progressos de la Liga Sagrada contra Turcos. Formada de las ultimas cartas de Italia, y el Norte. S. I., Sebastián de Armendáriz, [1686]. CBDRS0003609.

48. Relacion historica Del año 1686. Tocante al estado, sucessos, y progressos de la Liga Sagrada contra Tvrcos. Formada de las cartas de Italia, y el Norte. Publicada el Martes 76. de Iulio. Nuevas particularidades de las cosas de Polonia, y Moscovia. Terminos inmediatos de obrar en que estavan los Exer- 
citos Imperiales. Buda amenazada, y probablemente yà atacada. Nuevas vltimas de Tekeli. Breve relacion del inciendio de Venecia. Confirmacion del de Belgrado, y noticia de otros en Turquia. Resumen del Tratado mas amplio, y cumplido entre Polacos, y Moscovitas, y Carta cuiosissima al mesmo proposito. Nuevas mas frescas del Campo Imperial, y sitio de Buda. [Madrid], Antonio Román-Sebastián de Armendáriz, 1686. CBDRS0000971.

49. Relacion historica Del año 1686. Tocante al estado, sucessos, y progressos de la Liga Sagrada contra Tvrcos. Tomada de la sultimas cartas del Norte, y Extraordinairo, que llegò a esta Corte, despachado del Señor Emperador. Publicada el Martes 1. de Octubre. Movimientos del Exercito de Polonia, con intentos de imponderables consequencias. Relacion distinta de la vitoria conseguida à 74. de Agosto, Vispera de Nvestra Señora, por los Imperiales, contra el socorro que queria entrar en Buda. Otro arrojo de los Infieles contra las Lineas, el dia 23. con destrozo de muchos. Serie de operaciones entre uno, y otro sucesso asta la esforçada exugnacion de la Plaza. Particularidades bien notables, que hasta aora se han tenido de la mesma expugnacion. [Madrid], Antonio Román-Sebastián de Armendáriz, 1686. CBDRS 0000953.

50. Relacion historica Del año 1686. tocante al estado, svccessos, y progressos de la Liga Sagrada contra Tvrcos. Formada de las ultimas cartas de Italia, y el norte. Publicada el Martes 27. de Mayo. Continuacion de grandes prevenciones en Polonia, y toma de un gran comboy, que iba à Kameniez. Buenas nuevas de Moscovia, y Persia. Poco caso, y desconfiança que hazen los Turcos de Tekeli. Derrota de los Tartaros, que venian en su ayuda. Otros felices sucessos en ambas Vngrias. Vitoria de venecianos en la Morea, con liberacion de la Plaza de Chelafà del Asedio puestola porlos Turcos, y fuga vilissima de su Exercito, con perdida comsiderable. [Madrid], [Sebastián de Armendáriz], 1686. CBDRS0000967.

51. Relacion historica Del año 1686. Tocante al Estado, svccessos, y progressos de la Liga Sagrada contra Trrcos. Formada de las ultimas cartas de Italia, y el Norte. Publicada el Martes 7. de Mayo. Persistencia de las buenas disposiciones en Polonia. Sitio, y ataque de la Plaza de Mongatz. Recelos del proceder del Principe Transilvano. Varios rencuentros venturosos de los Imperiales con los Turcos: VItimas nuevas de Utalia con buen semblante, tocante à las disposiciones contra el enemigo comun. [Madrid], Antonio Román-Sebastián de Armendáriz, 1686. CBDRS0000966. 
52. Relacion historica Del año 1686. Tocante al estado, svcessos, y progressos de la Liga Sagrada contra Turcos. Formada de las vitimas cartas de Italia, y del Norte. Publicada el Martes 12. de Março. Diligencias con que se adelantan los aprestos de Polonia para la Campaña deste Año. Relacion distinta del Estado postrado de las cosas de los Otomanos. Nuevas vitimas de Tekeli. Aprestos, y disposiciones de la Sagrada Religion de San Iuan para la Campaña. Nuevos auxilios en aumento del Exercito Imperial. [Madrid], Sebastián de Armendariz, [1686]. CBDRS 0004942.

53. Relacion historica Del año 1686. Tocante al estado, svcessos, y progressos de la Liga Sagrada contra Trrcos. Formada de las vitimas cartas de Italia, y del Norte. Publicada el Martes 26. de Março. Declaracion del Rey de Persia contra tvrcos confirmada de muchas partes. Disposiciones grandes por la parte de Polonia para la Campaña, y otras noticias recientes de aquella Corte. Buenas esperanças de Moscovia. Prevenciones copiosissimas, y aceleradas de los Imperiales, assi de gente, como de provisiones. Nuevas vitimas de Italia, y buelta de vn Correo, con ofrecimiento considerable al Rey de Polonia. [Madrid], [s. i.], [1686]. CBDRS 0004943.

54. Relacion Historica Del año 1686. Tocante al estado, svcessos, y progressos de la Liga Sagrada contra Tvrcos. Formada de las vitimas cartas de Italia, y del Norte. Publicada el Martes 4. de lunio. Tratado concluido entre Polacos y Moscovitas contra Turcos. Confirmacion del ajuste con el Principe Transilvano, y principios de su execucion. Vitoria obtenida de vn gruesso de 7600 . Imperiales contra 3000. Turcos. Navegacion de los Auxiliares de Italia à Levante. [Madrid], Antonio Román-Sebastián Armendáriz, [1686]. CBDRS0004845.

55. Relacion historica Del año 1686. Tocante al estado, svcessos, y progressos de la Liga Sagrada contra Trrcos. Formada de las vitimas cartas de Italia, y del Norte. Publicadas el Martes 23. de Abril. Mejoria del Rey de Polonia, de vn gran corrimiento. Sitio, y bombardeo de la Fortaleza de Mongatz. Toma del Fuerte de Zirvar, por los Vngaros. Incendio del Gran Varadin. Relacion distinta del numero, y calidad del Exercito Imperial. Vltimas nueuas de Levante por Venecia, y Liorna. Madrid, Antonio Román-Sebastián de Armendáriz, [1686]. CBDRS0004941.

56. Relacion Historica Del año 1686. Tocante al estado, svcessos, y progressos de la Liga Sagrada contra Tvrcos. Formada de las vitimas cartas de Italia, y el Norte. Publicada el Martes 17. de Diziembre. VItimas nuevas de la retirada del Exercito de Polonia à Quarteles. Rendicion de la Fortaleza de Sic- 
klosch, ocupacion de la de Darda cabeza de la Pvente de Essek, y quema de la mesma Pvente por los Imperiales. VItimas noticias de Venecia, por falta de las de Levante, detenidas de los malos tiempos. [Madrid], Antonio RománSebastián de Armendáriz, [1686]. CBDRS0004850.

57. Relacion historica Del año 1686. Tocante al estado, svcessos, y progressos de la Liga Sagrada contra Tvrcos. Formada de las vitimas cartas de Italia, y el Norte. Publicada el Martes 19 de Noviembre. El Exercito de Polonia, encaminado à ganar la Grande y Cvmplida Vitoria, que muy cierta se ha sabido por las Cartas de Viena. Sitios de Seguedin, y Cinclo Iglesias, y confirmacion de la Toma de Simonthorna. Particularidades resumidas de la conquista de Napoles de Romania. Su fortaleza, è importancia. Nuevos disignios del Capitan General Morosini. Conquista de la Plaça de Sing, en la Dalmacia. [Madrid], Antonio Román-Sebastián de Armendáriz, [1686]. CBDRS0004959.

58. Relacion historica Del año 1686. Tocante al estado, svcessos, y progressos de la Liga Sagrada contra Tvrcos. Formada de las vitimas cartas de Italia, y el Norte. Publicada el Martes 2. de Iulio. Buenas disposiciones de Polonia. Gran fidelidad del Conde Petenhasi. Estado de los Imperiales inmediato à las operaciones, con la mejoria de los Señores Duques de Lorena, y Baviera. Rompiò yà el Principe de Transilvania con los Turcos. Sucessos afortunados de Venecianos en Dalmacia, y otras partes. Madrid, Antonio Román-Sebastián de Armendáriz, 1686. CBDRS0000969.

59. Relacion historica Del año 1686. Tocante al estado, svcessos, y progressos de la Liga Sagrada contra Turcos. Formada de las vitimas cartas de Italia, y el Norte. Publicada el Martes 3. de Diziembre. Confirmacion de la gran Vitoria de Polonia por Italia: pero mas distinta, por el Norte. Expvgnacion de las dos importantes Plaças de Segvedin, y Cinco Iglesias, y vitoria insigne conseguida contra el Exercito Turco, que quiso socorrer la primera. Noticias curiosas tocante a lo que se dispone de Buda. VItimas nueuas de Venecia, y Levante. [Madrid], Antonio Román-Sebastián de Armendáriz, [1686]. CBDRS 0004867.

60. Relacion Historica Del año 1686. Tocante al estado, svcessos, y progressos de la Liga Sagrada contra Tvrcos. Formada de las vitimas cartas de Italia, y el Norte. Publicada el Martes 30. de lulio. Noticias vltimas de Polonia inmediatas à la salida à la Campaña. Varias noticias curiosas de la Transilvania, y de la Vngria Superior. Nueva derrota, dada de los Imperiales à Tekelì. Principio, y progressos del Assedio de Buda. Relacion de la Toma de Navarin Viejo, 
y Nvevo, con la derrota del Exercido Infiel en la Morea, segun ha venido de Venecia, y Milàn. [Madrid], Antonio Román-Sebastián de Armendáriz, [1686]. CBDRS0004958.

61. Relacion historica Del año 1686. Tocante al Estado, y svccessos, y progressos de la Liga Sagrada contra Tvrcos. Formada de las ultimas cartas del norte, è Italia. Publicada el Martes 12. de Febrero. Mal despacho del embiado de la muger de Tekeli en la Corte de Polonia. Incendio horrible en la ciudad e Mescov. Garrote dado al Seraskier Cheitan. Tekeli aun vivo, y preso. Successos vitoriosos, y de grandes consequencias en la Vngria Superior. VItimas noticias de Levante por la via de Venecia. [Madrid], Antonio Román-Sebastián de Armendáriz, [1686]. CBDRS0000952.

62. Relacion historica del año 1687: tocante al Estado, sucessos y progressos de la Liga Sagrada contra turcos formada de las ultimas cartas de Italia y el norte, publicada el martes 20 de mayo. S. I., [Sebastián de Armendáriz], 1687. CBDRS0003790.

63. Relacion historica del año 1687 : tocante al estado, sucessos, y progressos de la Liga Sagrada contra turcos, formada de las ultimas cartas de Italia y el Norte, publicada el martes 74 de Enero. [Madrid], Antonio Román-Sebastián de Armendáriz. 1687. CBDRS0003784.

64. Relacion historica del año 1687 : tocante al estado, sucessos, y progressos de la Liga Sagrada contra turcos, formada de las ultimas cartas de Italia, y el Norte, publicada el martes 18 de março. [Madrid], Antonio Román-Sebastián de Armendáriz, 1687. CBDRS0003786.

65. Relacion historica del año 1687 : tocante al estado, sucessos, y progressos de la Liga Sagrada contra turcos, formada de las ultimas cartas de Italia, y el Norte, publicada el martes 8 de abril. [Madrid], Sebastián de Armendáriz, 1687. CBDRS0003788.

66. Relacion historica Del año 1687. Tocante al estado, svccessos, y progressos de la Liga Sagrada contra Tvrcos. Formada de las vitimas cartas de Italia, y el Norte. Publicada el Martes 18. de Febrero. Primera Audiencia dada por el Señor Rey de Polonia à los Embajadores de Moscovia. El gran Visir en camino para Constantinopla. Quema de los Arrabales de Sigeth, con una prodigiosa cantidad de bastimentos, y forrage, y consequencas desta hazaña. Determinacion de bombardear à Agria. Buen estado de las cosas de Venecianos en la Morea. [Madrid], Antonio Román-Sebastián de Armendáriz, 1687. CBDRS 0000956. 
67. Relacion historica Del año 1687. Tocante al estado, svcessos, y progressos de la Liga Sagrada contra Trrcos. Formada de las ultimas cartas de Italia, y el Norte. Publicada el Martes 25. de Março. Disposiciones en Polonia para grandes cosas. Ratificacion de los tratados con Transilvania. Confirmacion de la segunda derrota dada à Tekelì, y de su herida. Variedad de noticias tocante à su persona. Feliz avio de las prevenciones del Señor Emperador. Estado actual desesperado de los Turcos, y peligro del Sultàn. [Madrid], Antonio Román-Sebastián de Armendáriz, 1687. CBDRS0000957.

68. Relacion Historica del año de 1687. Tocante al Estado, Sucessos, y progressos de la Liga Sagrada contra Turcos. Formada de las ultimas cartas de Italia, y el Norte : publicadas en Sevilla, Sabado 18 de Octubre de 1687. SeviIla, Cristóbal López, 1687. CBDRS0003616.

69. Relacion historica del Año M. DC. LXXXVII. Tocante al estado, svcessos, y Progressos de la Liga Sagrada Contra Tvrcos. Formada de las ultimas cartas de Italia, y el Norte. Publicada el Martes 3. de lunio. Buenas disposiciones de Polonia, y Moscovia. Nuevas diligencias del Conde de Carafa, contra los complices en la conspiracion. Sustancia de la Carta, que ultimamente escriviò el Gran Visir, tocante à solicitar la Paz. Avio presuroso de la Campaña. Defensa Gloriosa, Liberacion de la Plaza de Sing, del assedio puestola por los Turcos. [Madrid], Antonio Román-Sebastián de Armendáriz, 1687. CBDRS0000975.

70. Relacion historica Del Año M. DC.LXXXVII. Tocante al estado, svcessos, Y Progressos de la Liga Sagrada Contra Tvrcos. Formada de las ultimas cartas de Italia, y el Norte. Publicada el Martes 17. de lunio. Buenas disposiciones de Polonia. Gran cuydado con que và restaurandose la Ciudad de Buda. Respuesta ultima del Principe Hernàn de Baden al Gran Visir. Tekelì yà sin gente, y sin credito, despues de descubierta la conspiracion. Particularidades antes no sabidas de la liberacion de Sing. [Madrid], Antonio Román-Sebastián de Armendáriz, 1687. CBDRS0000976.

71. Relacion historica Del Año M.DC. LXXXVII. Tocante al estado, svcessos, Y Progressos de la Liga Sagrada Contra Tvrcos. Formada de las ultimas cartas de Italia, y el Norte. Publicada el Martes 15. de lulio. estado de las cosas de Polonia inmediato à començar la Campaña. Nuevas muy particulares de Turquia. Dificultades que hallan los Infieles en juntar Tropas. Sucesso brioso, y de mucho credito à los Vssares Vngaros. Saqueo, è incendio de la Ciudad Turca de Lippa. Escapose Tekeli, que se hallava en ella Continuacion de la 
solicitud de su muger, para ajuste pero todavia dificultoso. El Señor Duque de Lorena absoluto en el mando de las Armas. La Armada de Venecia libre de peste. [Madrid], [Antonio Román]-Sebastián de Armendáriz, 1687. CBDRS0000977.

72. Relacion historica Del Año M.DC.LXXXIX. Tocante al estado, svcessos, Y Progressos de la Liga Sagrada Contra Tvrcos. Formada de las vitimas cartas de Italia, y el Norte. Publicada el Martes 5. de Abril. Procedese con lentitud en las Cortes de Polonia. Proposiciones de un Embajador Tartato à aquella Corona, pero sin fundamento por varios motivos. Entrada del Presidio Imperial en Zigeth. Coloquio curiosos entre el Bajà, y el Conde de Taun. Buenas esperanças de Canisa. Prosiguense las conferencias con los Embiados Turcos, con apariecias de que terminen las Pazes. Poca salud del Serenissimo Dux de Venecia, y mudança en el mando de las Armas de la Seren. Republica en Levante. Madrid, Antonio Román-Sebastián de Armendáriz, 1689. CBDRS0000993.

73. Relacion historica Del Año M.DC.LXXXIX. Tocante al estado, svcessos, Y Progressos de la Liga Santa Contra Tvrcos. Formada de las ultimas cartas de Italia, y el Norte. Publicada el Martes 7. de Março. Progresso de la Dieta de Polonia, y nuevos daños executados de los Tartaros en aquel Reyno. Nuevas de Turquia por via de Ungria, y Venecia muy favorables à la Christiandad. Todas las Plazas Turcas bloqueadas, boqueando. Rendicionde Zigeth à las Armas Imperiales. Su Descripcion, y importancia. VItimas nuevas de Venecia de grande expectacion para la causa publica. [Madrid], Antonio RománSebastián de Armendáriz, 1689. CBDRS0000992.

74. Relacion historica Del año M.DC.LXXXVII. Tocante al estado, sucessos, Y Progressos de la Liga Sagrada Contra Turcos. Formada de las ultimas cartas de Italia, y el Norte. Publicada el Martes 18. de Noviembre. Conclusion de las Campaña de Polonia. Continuacion de los progressos de los Imperiales en las Provincias Turcas de la Rascia, y Esclavonia. Confirmacion sija del Levantamiento del Exercito Turco, contra el Gran Visir, su fuga a Belgrado, y de alli la buelta de Constantinopla. Particularidades de la toma de Castelnovo. [Madrid], [Antonio Román]-Sebastián de Armendáriz, 1687. CBDRS0000999.

75. Relacion historica del Año M.DC.LXXXVII. Tocante al estado, svcessos, Y Progressos de la Liga Sagrada Contra Tvrcos. Formada de las ultimas cartas de Italia, y el Norte. Publicada el Martes 16. de Diziembre. Noticias confirmadas de muchas partes, del grande abatimiento, y confusion de los Turcos. Viage 
de su Magestad Cesarea, y del Señor Archiduque Don loseph à Polonia, y su recibimiento. Nueva comparicion de Tekeli. Plaças, y Quarteles ocupados en Transilvania, y Relacion distinta del ajuste estipulado entre el Señor Duque de Lorena, y el Principe Abasi. Primera noticia de la toma de Agria. Diario de la expugnacion de Atenas. [Madrid], [Antonio Román]-Sebastián de Armendáriz, 1687. CBDRS0001001.

76. Relacion historica Del Año M.DC.LXXXVII. Tocante al estado, svcessos, Y Progressos de la Liga Sagrada contra Tvrcos. Formada de las ultimas cartas de Italia, y el Norte. Publicada el Martes 21. de Octubre. Segunda noticia de la Vitoria de los Moscovitas. El Rey de Polonia yà en el Exercito. Rehusa Su Mag. los ofreciminentos de los Turcos, para que se separe la Liga Sagrada. Estado actual de las cosas en ambas Vngrias. Diario de los principios del ataque de la Fortaleza de Catelnovo. [Madrid], Antonio Román-Sebastián de Armendáriz, 1687. CBDRS 0000997.

77. Relacion historica Del Año M.DC.LXXXVII. Tocante al estado, svcessos, Y Progressos de la Liga Sagrada Contra Tvrcos. Formada de las ultimas Cartas de Italia, y el Norte. Publicada el Martes 29. de Iulio. Determina el Rey de Polonia salir personalmente à Campaña. Relaciones individuales del Exercito Imperial, que manda el Señor Duque de Lorena, y del Otomano del Gran Visir. Aprieto en que se halla la Plaça Turca de Agria. Platicas de ajuste con la Princesa Ragotzi, y Bloqueo de Mongatz. Marchas del señor Duque de Lorena. Fuga de seis mil Tartaros al primer assomo del exercito del Señor Duque de Baviera. VItimas nuevas de Levante. [Madrid], Antonio Román-Sebastián de Armendáriz, 1687. CBDRS 0000979.

78. Relacion historica Del Año M.DC.LXXXVII. Tocante al Estado, svcessos, Y Progressos de la Liga Sagrada Contra Tvrcos. Formada de las ultimas Cartas de Italia, y el Norte. Publicada el Martes 7. de Octubre. Algunas noticias de las cosas de Polonia. Nueuas particularidades, y consequencias de la Vitoria de Darda. Resoluciones tomadas por los Señores Duques. Consternacion total de los Turcos, y esperanças de lograrla en breve. Primeras noticias de una grande victoria conseguida de los Moscovitas contra los Tartaros. Toma de Corinto, Castel Tornes, Misistra, \&c. por los Venecianos yà dueños absolutos de todo el gran Reyno de la Morea. [Madrid], Antonio Román-Sebastián de Armendáriz, 1687. CBDRS0000990. 
79. Relacion historica del año M.DC.LXXXVIII : tocante al estado, sucessos, y progressos de la Liga Sagrada contra turcos, formada de las ultimas cartas de Italia, y el Norte, publicada el martes 7 de liulio. [Madrid], Sebastián de Armendáriz, 1687. CBDRS0003807.

80. Relacion historica Del Año M.DC.LXXXVIII. Tocante al estado, sucessos Y Progressos de la Liga Sagrada Contra Turcos. Formada de las Ultimas Cartas de Italia, y el Norte. Publicada el Martes 23. de Março. Principio de las Cortes de Polonia. Prision de un Bajà, que iba à solicitar socorro para Alba-Real. Estado en que se halla aquella Plaça. Nuevas de Constantinopla, y lista de los Ministros, y Cabos, que han perecido, y padecido en la vitima revolucion. Vitoria reportada por el General Heisler Contra Tekeli, referida en una carta del mesmo General. VItimas noticias de Venecia. [Madrid], Antonio Román-Sebastián de Armendáriz, 1688. CBDRS0000981.

81. Relacion historica Del Año M.DC.LXXXVIII. Tocante al estado, svcessos, Y Progressos de la Liga Sagrada Contra Tvrcos. Formada de las ultimas cartas de Italia, y el Norte. Publicada el Martes 29. de lunio. Determinacion del Rey de Polonia de ir al Exercito à mandarle, en estando juntas sus fuerças. Procuran los Tartaros embalde, separar Su Mag. Polaca de la Liga con los Moscovitas. Relacion resumida de lo ocurrido en el bloqueo, y Rendicion de Alva Real; la gente que saliò, lo que se hallò en la Plaça, \&. Concurso acelerado de las fuerzas Imperiales à Esseck. Demolicion de la Palanca de la mesma ciudad de Esseck, de Petri-Varadin, \&c. Grandes Comboyes encaminados à la Armada de Venecia. Relacion individual de los Comandantes, Oficiales, y otras personas de cuenta, que vàn a Levante en el batallon de la Religion de S. Juan. [Madrid], [Antonio Román]-[Sebastián de Armendáriz], 1688. CBDRS 0000985.

82. Relacion historica Del Año M.DC.LXXXVIII. Tocante al estado, svcessos, Y Progressos de la Liga Sagrada contra Tvrcos. Formada de las ultimas cartas de Italia, y el Norte. Publicada el Sabado 3. de Enero. Felicidad con que se prosiguen las Cortes del Reyno de Vngria en Polonia. Prerrogativa gloriosa, è importante, assentada en ellas à los Padres de la Compañia de Jesus. Rendicion de la Ciudad de Agria, y sus relevantissimas consequencias. Relacion curiosa, que haze un Christiano escapado de Belgrado. Vltimas nuevas de Grecia, y Dalmacia. [Madrid], [Antonio Román]-Sebastián de Armendáriz, 1688. CBDRS0001002. 
83. Relacion historica Del Año M.DC.LXXXVIII. Tocante al estado, svcessos, Y Progressos de la Liga Sagrada Contra Tvrcos. Formada de las vitimas cartas De Italia, y el Norte. Publicada el Martes 4. de Mayo. Esperanças por la parte de Polonia, no obstante la separacion de la Dieta. Diversas disposiciones de los Impeirales para la Campaña. Nueva fuga de Tekeli al Gran Varadin. Rota sangrienta dada de los Imperiales à los Turcos en la Esclavonia. Exaltacion del Capitan General Moiorsini à la Dignidad de Dux de Venecia, \&c. Condiciones que se entiende quiere proponer al nuevo Sultan al señor Emperador para las Pazes. [Madrid], Antonio Román-Sebastián de Armendáriz, 1688. CBDRS0000983.

84. Relacion historica DelAño M.DC. LXXXVIII. Tocante al estado, sucessos Y Progressos de la Liga Sagrada Contra Turcos. Formada de las ultimas cartas de Italia, y el Norte. Publicada el Martes 20. de Enero. Noticias del mal estado de los Turcos por Polonia, y otras partes. Capitulacion de la ciudad de Agria. Coronacion del Avgvsto Rey de Vngria Joseph Primero. Obediencia que prestan à la Serenis. Republica de Venecia los naturales de la Provincia de Arcegovina. [Madrid], [Antonio Román]-Sebastián de Armendáriz, 1688. CBDRS0001012.

85. Relación nueva y verdadera en la que se avisan muchas cosas de Italia y de las victorias que han tenido contra el turco los Reyes de Polonia, y Hungría, en que se le han desbaratado, y muerto mucha gente, este año de 7624. También se avisa de la victoria que han tenido las galeras de Nápoles contra navíos de turcos, con otras cosas curiosas y de alegría. Sevilla, Simón Fajardo, 1624. CBDRS 0006281.

86. RELACION VERDADE / RA DE ESTE PRESENTE ANO (sic) DE SEYSCIENTOS $Y$ / ve ynte y tres,la qual trata de vna carta que le escriuio el gran Turco al I Rey de Polonia,amenaçandole con guerras porque no quiere ser ami- I go suyo,donde estan todos los ditados (sic) del Turco. Y otra carta en res- 1 puesta desta del Rey de Polonia,no haziendo caso de sus amena I ças,y amenaçandole,y defendiendo la santa Fe / Catolica. Sevilla, Iuan Serrano de Vargas, 1623. CBDRS 0006826A.

87. RELACION VERDADERA DE / este presente año de. 1623. la qual trata de vna Lcarta que le escriuio el gran Turco al Rey de / Polonia,amenaçandole con guerras por que no / quiere ser amigo suyo, donde estan todos los di / tados 
(sic) del Turco. Y otra carta en respuesta / desta del Rey de Polonia,no haziendo ca / so de sus amenaças, y amenaçando / le, y defendiendo la santa / fe Catolica. Granada, Iuan Munoz, 1623. CBDRS 0006826B.

88. Relacion verdadera de la gran vitoria que las armas del Reyno de Polonia han coseguido (por medio del Divino Auxilio, implorado de la Vniversal, Catolica, y Militante Iglesia) contra el Poder Otomano. Refierese el sangriento destroço que hizieron en los Turcos los Polacos; los ricos despojos que les quitaron; la Artilleria, viveres, y municiones que perdió el Enemigo, el dia 71 de Noviembre del año passado de 1673. Y assimismo se refiere, como el siguiente dia 12 de dicho mes, ganò el Exercito Christiano por assalto la Plaça de Chozim, passando à todos sus Moradores à cuchillo. Con licencia en Madrid, por Lucas Antonio de Bedmar. Año de 7674. Madrid, Lucas Antonio de Bedmar, 1674. CBDRS0000507.

89. Relación verdadera de la insigne victoria que alcanzó el rey de Polonia contra el gran duque de Moscovia, y otros confederados suyos, todos enemigos de nuestra Santa Fe, y de las coronas de la casa de Austria; enviada del ejército de su Majestad de Polonia, su fecha en 24 de marzo de 1624. [S. I.], Francisco de Ocampo, 1634. CBDRS 0006330.

90. RELACION VERDADERA DE LA MAYOR VITORIA QVE SE HA visto en nuestros tiempos, del Rey de Polonia, contra el Gran can, y multitud de Babaros. Dase cuenta de los muertos, y prisioneros, y el modo de pelear que vsan aquellas Naciones. Sevilla, Nicolás Rodríguez, [s. a.]. CBDRS0002935.

91. Relacion verdadera de las insignes vitorias que Dios Nuestro Señor ha sido servido co[n]ceder a las Armas del señor Juan Casimiro Rey de Polonia, contra las de Carlos Adolfo Rey de Suecia, que tyranicame[n]te se avia apoderado del Reyno de Polonia, intitula[n]dose Rey de aquellas dilatadissimas Provincias. Este año de 1656. Sevilla, Juan Gómez de Blas, 1656. CBDRS0003876.

92. RELACION / verdadera de nueuos auisos de los es- I tados de Italia, de los aparatos, preuenciones y rumores / de guerra, que al presente ay en el estado de Milán, Geno / ua, Venecia y Saboya, y otras partes. Del alegre recibi- I miento que nuestro santissimo Padre Vrbano Octauo / hizo en Roma al Principe de Polonia, y en Napoles el se- I ñor Duque de Alua. este (sic) año de 1625. [Sevilla], Simón Faxardo, 1625. CBDRS 0006294. 
93. Relacion verdadera del magnifico Aparato con que en la Ciudad de Barsobia se celebro la Dieta del dia 17. de Abril deste Año de 1683; en que se concluyó entre el señor Emperador, y el señor Rey de Polonia la Aliança, y Liga ofensiva, y defensiva contra, el Turco. Refierense los Capitulos della, y el juramento que hazen ambas Magestades en manos de su Santidad, por medio de los Eminentissimos señores Cardenales Pio, y Barberino, Protectores de ambas coronas: Con otras particularidades dignas de saberse. Madrid, Lucas Antonio de Bedmar, 1683. CBDRS0001972.

94. Relacion verdadera en la qual se da quenta de la elección que hizo la Dieta de Polonia para su nueuo Rey, en 79. de lunio deste año de 69. I los varios pareceres que en esta huuo, sobre qual auia de ser electo, y el fin que tuuo dicha eleccion. Traducida de lengua Italiana en nuestro Idioma. Zaragoza, Herederos de Pedro Lanaja, 1669. CBDRS0001994.

95. Relacion verdadera en que se da cuenta como el Rey de Polonia en dos batallas campales ha vencido al gran Turco, el orden de la guerra, el numero de los muertos, como los Turcos huyeron del exercito del Rey. Barcelona, Estevan Liberos, Gabriel Graells, 1622. CBDRS0001999.

96. Relacion verdadera, de un caso raro y maravilloso, sucedido en el Reyno de Polonia, para confirmacion de nuestra Santa Fe Catholica y confusion de los hereges, que con tanta instancia han procurado, y quieren contradezir a ella, donde trata como los hereges tiraron de balassos a un Santo Christo, el qual manò sangre por espacio de siere dias del lado, y el grande milagro que nuestro Señor hizo en favor de los Christianos. Barcelona, Estevan Liberos, Gabriel Graells, 1627. CBDRS0001985.

97. Relacion verdadera, en que se da noticia de las grandes prevenciones, Y Aparatos de Guerra con que ha salido à Campaña el Exercito del Invictissimo señor Emperador Leopoldo Ignacio de Austria, de quien es Generalissimo el Señor Duque de Lorena, despues que en Barsobia se concluyeron entre el Imperio, y Polonia los Tratados de firme Aliança, y Liga ofensiva, y defensiva contra el Turco. Refirese la Muestra General, que se hizo del Exercito Imperial, junto à Presburghali,l el dia 6 de Mayo deste presente Año de 7683. Y también se mencionan los regimientos que en dicha Muestra General se haIlaron; y el numero de Infanteria, y Cavalleria de que se comprende. Assimismo se refiere la Solemnidad con que el Nuncio de su Santidad publicò la Bula de Indulgencia Plenaria, y Remission de pecados, à culpa, y pena, concedida por Nuestro Santissimo Padre Inocencio XI. à todos los que en esta Guerra 
murieran en defensa de la Santa Fè Catolica: Absolución General que se diò a todo el Exercito Christiano: Magestuoso Combite que dicho señor Duque de Lorena, Generalissimo de las Armas Imperiales, hizo al señor Emperador, à los Potentados de su Sequito, y demàs Cabos del Exercito: Cuyas Valerosas Armas le tienen ya sitiada al Turco la Fuerte Plaça de Estrigonia: Con otras particularidades que verà el Curioso. Madrid, Lucas Antonio de Bedmar, 1683. CBDRS 0002005.

98. Relaciones extraordinarias de la feliz, e importante vitoria. Consegvida de las reales Armas de Polonia contra vn Exercito de Turcos, encaminados al socorro de la Ciudad de Kameniez. Del recibimiento solemne hecho en la Cote de Polonia as Embajador Extraordinario de la Serenissima Republica de Venecia. Y de la marcha del poderosissimo Exercito del Sofi de Persia contra la Gran Ciudad de Badget, ò Babilonia. Ocupada de los Otomanos. Tradvcidas todas tres de bvenos originales Latinos, è Italianos con toda fidelidad. Publicanse à 5 de Setiembre 1684. [Madrid], Antonio Román-Sebastián de Armendáriz, 1684. CBDRS0000933.

99. Salida en pvblico, a cavallo, del Rey nvestro Señor Don Carlos Segundo, que Dios guarde, à dar gracias al Real Convento de Nuestra Señora de Atocha el Lunes 8. de Noviembre de 1683. por la Gran Vitoria conseguida del Imperio, y Polonia contra el Turco: Entrada en publico al Retiro, que executò el señor Embaxador de Alemania el Domingo 7. de dicho mes. Fiestas de Roma sobre la misma Vitoria, y Celebridad de la Corte Catolica. [Madrid], Lucas Antonio de Bedmar y Baldivia, 1683. CBDRS0004697.

100. Toma, y recvperacion de la gran plaza de Estrigonia, conseguida el dia 27. de Octubre deste Año de 1683. por las Armas Imperiales, que govierna el Serenissimo Señor Duque de Lorena, cuya feliz Nueva llegò à esta Corte el Miercoles 24. de Noviembre de dicho Año, por Correo Extraordinario de Flandes, embiado del señor Marquès de Grana, su Governador. Derrota qve en frente de dicha Plaça diò con sus Vitoriosos Imperiales à tres escogidos Regimientos de los Barbaros. Y progressos del Señor Rey de Polonia, en que se refieren notables circunstancias. [Madrid], Lucas Antonio de Bedmar y Valdivia, 1683. CBDRS 0004696.

101. Verdadera Relacion de la vitoria que han tuuido los Españoles, Poloneses, y Vngaros, contra los Turcos, y Tartaros, y presa dellos, con la presa de catorze vaxeles. Barcelona, Esteve Lliberós, 1628. CBDRS0004536. 
102. Verdadera Relacion. En que se refiere por menor todo lo sucedido en la derrota del Exercito Otomano, con dos Cartas del señor Rey de Polonia, para su Santidad, y Republica, Veneciana. Sevilla, Juan Francisco de Blas, 1683. CBDRS 0003801.

103. Verdadera, y nueva relacion de las sangrientas guerras del reyno de Polonia, contra el comun enemigo de la christiandad el Gran Turco, adquirida de personas de toda suposicion, y autoridad verdadera. Dase cuenta del feliz sucesso que tuvieron las armas polacas, y de la mortandad que en los turcos hizieron, y como el postrer choque fue de poder a poder, y como quedaron muertos en la batalla mas de ci'en mil turcos, y de las riquezas, assi oro, como plata, que se le quitò a poder de armas. Valencia, Benito Macé, 1674. CBDRS0006062.

104. Verdadero retrato del monstruoso pescado, que se hallò en Alemania, en vn rio del Reyno de Polonia. Sevilla, Juan Serrano de Vargas y Ureña, 1624. CBDRS0006544A

105. Verdadero retrato del monstruoso pescado, qu[e] s[e] hallò en Alemania, en un rio del Reyno de Polonia. Granada, 1624. CBDRS0006544B.

106. Alfantega y Cortés, Francisco: VERDADERA RELACION DE LA CORONACION DEL SERENISSMO IVAN CASIMIRO, PRINCIPE DE POLONIA, POR LA MVERTE DEL PODEROSISSIMO REY VLADISLAO QVARTO. Madrid, Julián Paredes, 1649. CBDRS0005048.

107. Fernández Navarrete, Pedro: Carta de Lelio Peregrino a Stanislao Borbio privado del Rey de Polonia. Por el licenciado Pedro Fernandez Nauarrete, Canonigo de Santiago, Capellan, y Secretario de su Magestad, y de la Reyna nuestra señora, y de Camara del señor Cardenal Infante. Con privilegio. En Madrid, En la Imprenta Real. Año M.DC.XXV. Madrid, Teresa Iunti, Imprenta Real, 1625. CBDRS0000252A.

108. Fernández Navarrete, Pedro: Carta de Lelio Peregrino a Stanislao Borbio privado del Rey de Polonia. Por el licenciado Pedro Fernandez Nauarrete, Canonigo de Santiago, Capellan, y Secretario de su Magestad, y de la Reyna nuestra señora, y de Camara del señor Cardenal Infante. Con privilegio. En Madrid, En la Imprenta Real. Año M.DC.XXV. [Madrid], [s. i.], [1625]. CBDRS0000252B.

109. Martín Braones, Alonso: A MAYOR GLORIA DE DIOS. LYRICA RELACION, DE LA FIESTA, QVE LA ILVSTRISSIMA HERMANDAD, QVE SIEMPRE FERVOROSA ASSISTE AL CVLTO DEL SAMTISSMO. SACRAMENTO en el Templo del 
señor San Clemente, Sagrario de la Santa Patriarchal, y Metropolitana Iglesia de Seuilla, HIZO EN ACCION DE GRACIAS DE LA célebre victoria, con que fauoreciô a Dios nuestro Señor las Armas del señor Emperador, governadas por el señor Rey de Polonia, y su Alteza el señor Duque de Lorena, contra el poder Otomano, teniendo sitiada la Plaza de Viena, este año de 1683. Sevilla, Juan Francisco de Blas, 1683. CBDRS 0000094.

110. Morales, Juan Bautista de: Declaracion de las prodigiosas señales del monstruoso pescado que se hallò en un rio de Polonia en Alemania, cuyo retrato se embiò a España este año de 1624 ... por luan Baptista de Morales su autor. Sevilla, Francisco de Lyra, 1624. CBDRS0003473A.

111. Morales, Juan Bautista de: Declaracion de las prodigiosas señales del monstruoso pescado que se hallò en un rio de Polonia en Alemania, cuyo retrato se embiò a España este año de 1624 ... por luan Baptista de Morales su autor. Sevilla, Simón Faxardo, 1624. CBDRS0003473B.

112. Ortiz de la Fuente, Diego: DECLARACION DE LOS I GRANDES PRODIGIOS, Y ESPANTOSOS MONS- I truos que se han visto en el mundo, y explicacion de tres Lunas que este / año passado de mil y seyscientos y veynte y quatro se vieron en / Roma, con otros portentos que se han visto, que an / causado admiracion. I Por el Licenciado Diego Ortiz de la Fuente Abogado,y natural de Montilla. Seuilla, Simón Faxardo, 1625. CBDRS 0006547A.

113. Ortiz de la Fuente, Diego: VARIOS PRODIGIOS I Y PRODIGIOSOS MONSTRVOS, OVE SE AN VISTO EN EL MVN- I do. Y explicacion de lo qsinifican el mōstruoso pescado del Rio de Polonia I en Alemania, y el velludo monstruo q pario Madama Ana muger de Tomas I Drac Conde de Apuria y Cariaen la Ciudad de Londres, Corte del Rey / de Inglaterra en el Año de mil y seiscientos y veinte y quatro, y de las / tres Lunas que en el mismo año se vieron en Roma. I Por el licēciado Diego Ortiz de la Fuēte Abogado y natural de Mōtilla. Montilla, Iuan Batista (sic) de Morales, 1624. CBDRS 0006547B.

114. Rey de Polonia, Juan III Sobieski: Copia verdadera, y fielmente tradvcida de la Real Carta que el Serenissimo Rey de Polonia imbiò á 15. de Agosto deste Año de 1684. à nuestro Beatissimo Padre Innocencio XI. Barcelona, [s. i.], 1684. CBDRS 0004793.

115. Sojo, Benito de (S.I): Copia de vna carta del Padre Benito de Soxo de la Compañia de lesus ... escrita a los padres de la Compañia de lesus de Roma, Madrid, Granada y Cordoua. Su fecha en veynte y tres de agosto, de seycientos 
y veynte y siete. Para mayor intelligencia de los varios sucessos que aqui se refieren, aduierto, q[ue] la Prusia se diuide en tres partes: Vna pertenece al Rey de Polonia. Otra al Obispo su hijo. Llamese el Obispo Barbiense ... La tercera parte ... es del Moso Grande Burico ... Al presente nuestro ... Rey de Polonia tiene dos exercitos en campaña contra el Suezo: vno en Prusia ... con intento de cobrar las fortalezas, ciudades y otros lugares, que ... conquistò el Suezo ... Refiero ... el milagro de Constantinopla, en el Templo Griego, o Ruteno de santa Sofia ... Cerremos esta relacion con dezir que en Moscobia ... ha auido terribles temblores de tierra ...-- Lo imprimiò en Granada : Bartolome de Lorençana y Vrueña [sic] ..., 1628. Granada, Bartolomé Lorenzana, 1628. CBDRS 0005977.

116. Sojo, Benito de (S.I.): RELACION / VERDADERA DE / LA MVERTE Y MARTIRIO QVE DIERON / los Cismaticos de la Rusia en el Reyno de Polonia, a su Azçobispo, Ila / mado losafat, porque les exortaua se conuirtiessen a la Santa Fe Cato- I lica, y detestassen su deprauada cisma y error. Dase cuenta de los gran / des castigos que por el Serenisimo, y muy Catolico Sigismundo Rey I de Polonia se hizo a los agressores, y culpados en este delito. Año de / 7624. Fue embiada por vn Padre la Compañia de IESVS, I Doctor en Santa Theologia de la prouincia de Polonia, a / los Padres de Andaluzia de la I misma Religion. [Sevilla], Simón Fajardo, 1625. CBDRS0004857.

117. Sojo, Benito de (S.I.): Victorias que el rey de Polonia ha tenido contra los herejes de Suecia; y espantosos milagros que Dios ha obrado en aquel reino, que los católicos tienen por anuncio de sus buenos sucesos, y los enemigos por señales de su total destrucción. Dase cuenta de un espantoso caso que sucedió en la mezquita de Constantinopla, estando dentro el Turco, al tiempo de celebrar las ceremonias de su maldita secta. Sevilla, Francisco de Lira, 1628. CBDRS 0006307.

118. Titlewski, Mathias: NARRATIO / DE PRAELIIS / GESTIS / inter / POLONUM, ET TURCAM /Annis 1620.\& 1627. IAD SERENISSIMUM CAROLUM/Hispaniarum Infantem / per / MATTIAM TYLEWSKI | nobilem Polonum. | MATRITI | Apud Thoman Iuntam Typographum Regium / Anno M.DCC. XXIII. Madrid, Tomás lunti, 1623. CBDRS0007020B.

119. Titlewski, Mathias: RELACION / DIARIA DE / LAS GVERRAS TENI- / das entre Polacos y Turcos por / los años 1620. I y 1627. I Dirigida al Serenissimo Principe Don Carlos I Infante de las Españas. I POR MATHIAS TITLEVVSKI. I Cauallero Polaco. I [Orl. tip.] / CON PRIVILEGIO. I EN MADRID, Por Tomas lunti, Impressor del Rey N. S I Año M.DC.XXIII. Madrid, Tomás lunti, 1623. CBDRS0007020C. 